\title{
Alternative employment and well-being:
}

Contract heterogeneity and differences among individuals

\section{Claudia Bernhard-Oettel}

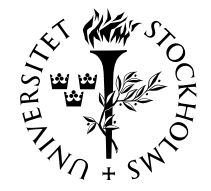

Stockholm University 
CClaudia Bernhard-Oettel, Stockholm 2008 Cover Photo: (C) Claudia Bernhard-Oettel

ISBN (978-91-7155-691-2)

Printed in Sweden by US-AB, Stockholm 2008

Distributor: Department of Psychology, Stockholm University 


\section{Abstract}

The increasing use of temporary and part-time employment in recent decades was initially expected to lead to negative effects for the individual. The empirical evidence, however, has been equivocal and the consequences are therefore still unclear. This thesis adopts a psychological approach to alternative employment by investigating how heterogeneity in employment contracts together with individual differences associate with work attitudes and subjective well-being. It comprises four studies in which questionnaire data is used to study differences among temporary workers (Study I \& II) and differences in the alternative workforce (fixed-term, on-call, and parttime workers) as compared to permanent full-time workers (Study III \& IV), in order to analyze the impact of different types of contracts together with individual differences. Study I found that attitudes, role stress, and health varied across different patterns in individuals' backgrounds and contract forms. Study II demonstrated that distinct patterns of voluntary and involuntary contract motives and of work involvement associated with differences in reported work-related and general well-being. Study III showed that well-being and organizational attitudes were related to individuals' job and contract preferences and, to some degree, heterogeneity in contract types. Study IV revealed that individuals' perceptions of job conditions (control, demands, and job insecurity) predicted well-being, whereas type of employment contract was found to be less important. Employment contract forms, however, interacted with individual diversity in Study III and IV. The thesis concludes that differences among individuals are important for understanding the implications of different types of alternative employment contracts. Future research should focus on these interactive mechanisms to better understand the consequences of alternative employment forms.

Keywords: Employment contract, temporary work, part-time work, individual characteristics, contract motives, work involvement, job characteristics, work-related attitudes, well-being, health. 



\section{Acknowledgements}

The last sentence is written, the book has been printed - and here it is: my $\mathrm{PhD}$ thesis. So I am proud, happy that it is done, and thankful for all the support I received on the way. To begin with, the research reported in this thesis was made possible through grants from the Swedish Council for Working Life and Social Research, the Stockholm County Council, and the $5^{\text {th }}$ framework programme of the EU. Apart from the economic sponsoring, there were a number of people who contributed to the completion of this thesis in many different ways.

Above all, I am greatly indebted to my supervisor, Professor Magnus Sverke. There is a lot I want to thank you for, but most of all, thanks for getting me interested in research to begin with, and for always being available for support and guidance. Thanks also for tirelessly reading my long manuscripts, and for constantly responding with lists of wise and inspiring comments that helped to improve my work. I really have enjoyed working with you! Professor Kerstin Isaksson, my co-supervisor, thank you for the opportunity to work in the PSYCONES project, for sharing your knowledge on psychological contracts with me, and for giving constant positive and encouraging feedback. I would also like to thank my cosupervisor, Professor Gunnar Aronsson, for taking on the role when I already had come a bit on the way. Thank you for all the good advice, and the inspiring discussions on the new world of working. Furthermore, I want to express gratitude to Prof. Lars R. Bergman, for his kind support and guidance in the world of pattern approaches and cluster analysis.

Among my former colleagues from the National Institute of Working Life, I would like to give particular thanks to Katalin Bellaagh, Wanja Astvik, Miriam Eliasson, John Sjöström, and Malin Bolin for giving their support and the opportunity to discuss both important professional and private matters at any time. Erik Berntson, you have had many roles as my 'fellow doctoral student' from the Department of Psychology, and recently, even as my office mate. Thanks for all the laughs and support, as well as good advice about the do's and don't's in Swedish academic and non-academic life.

At the Department of Psychology, I extend many thanks to my colleagues from the Division of Work and Organizational Psychology (in no particular 
order): Katharina Näswall, Johnny Hellgren, Gunn Johansson, Ulla Gautam, Stephan Baraldi, Helena Falkenberg, Caroline Cederström, Niklas Hansen, Teresia Andersson-Stråberg, Kristina Danilov, Victoria Blom, Anne Richter, Klas Gustafsson, Lars Häsänen, Eva Mauritzson-Sandberg, Ingemar Torbiörn, Camilla Kylin, and Petra Lindfors.

Working in a European project has introduced me to many nice and great international colleagues, who have given me invaluable insights into the world of work psychology and made working in the PSYCONES project a great experience. Thanks to every one of you, and particularly Prof. Hans De Witte and Dr. Nele De Cuyper at the Katholieke Universiteit Leuven, Belgium, for your great co-authorship, many inspiring discussions, and the constant updates on gossip and private matters, that keeps a good work life and non-work life balance. Thanks also to Jeroen de Jong, Thomas Rigotti, Inmaculada Silla, and Noga Chipman-Stainvarts for sharing your coauthorship, knowledge, and friendship with me.

This work would have been impossible without the administrative, technical, and librarian support from a number of employees at the National Institute for Working Life and the Department of Psychology, and I wish to thank all of you. A special thank goes to David Speeckaert for helping me with the language and much more, and to my friends and family, who let me use their photographs for the cover, and helped me with the lay-out.

To all my friends outside of the academic world and to my family, it is impossible to list all your names here, but I want to thank you for constantly reminding me that there is a life apart from work, and for making this part meaningful, filled with good times and lots of laughs. Thanks for listening and encouraging me, giving support and believing in me even in times when I myself have been in doubt. Mom and dad, you have always encouraged me to go my own way, and to live my dreams. Thank you for everything.

Finally, my heartfelt gratitude goes to the two men in my life. To Wolfram, for your extraordinary love and friendship, and never-ending patience and support. You have made this and other journeys with me and I hope there are many more to come. To Mark, for showing me that a $\mathrm{PhD}$ is far from the only thing that is important, and for sharing your own little world and fantastic insights with me. I love you!

Claudia Bernhard-Oettel

Stockholm, July 2008 


\section{List of studies}

I. Bernhard, C. \& Sverke, M. (2003). Work attitudes, role stress and health among different types of contingent workers in the Swedish health care sector. Research \& Practice in Human Resource Management, 11, 1-16.

Reprinted with permission (@ Sage Publications Ltd).

II. Bernhard-Oettel, C., Isaksson, K. \& Bellaagh, K. (in press). Patterns of contract motives and work involvement in temporary work: Relations to work-related and general well-being. Economic and Industrial Democracy

Reprinted with permission (@ Sage Publications Ltd).

III. Bernhard-Oettel, C., De Cuyper, N., Berntson, E. \& Isaksson, K. (submitted). Job and contract preferences in different employment forms: Relations to well-being and organizational attitudes.

IV. Bernhard-Oettel, C., Sverke, M. \& De Witte, H. (2005).

Comparing alternative employment to permanent full-time work: How do employment contract and perceived job conditions relate to health complaints? Work \& Stress, 19, 301-318.

Reprinted with permission (ㄷ Taylor \& Francis Group). 



\section{Contents}

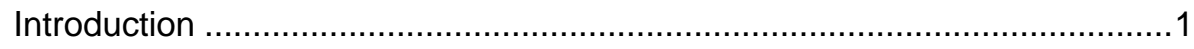

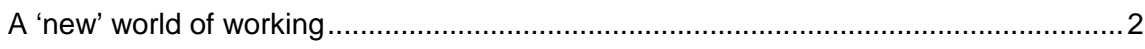

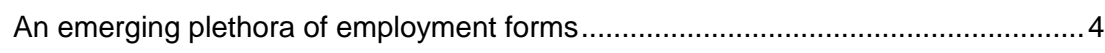

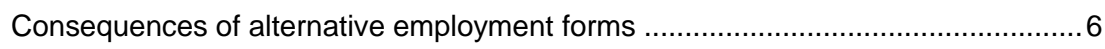

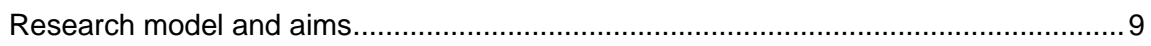

Heterogeneity of formal employment contracts …...................................13

The concept of employment status in different frameworks................................ 13

Dual labor market theory and flexible firm model ....................................... 13

Employment status in a core-periphery structure ..................................... 14

The qualitatively different conditions of employment contracts .......................... 16

The employment forms differentiated in this thesis.......................................... 18

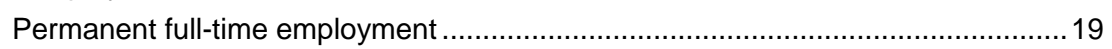

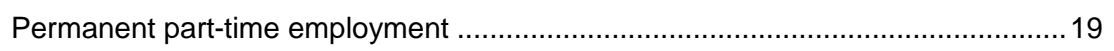

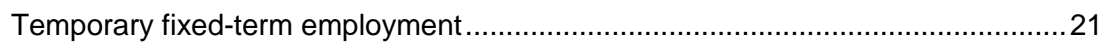

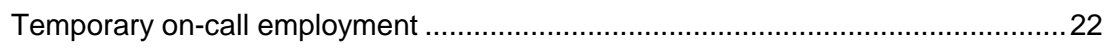

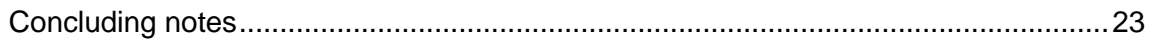

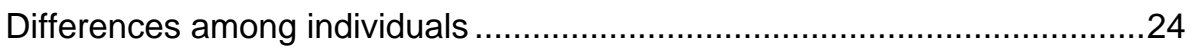

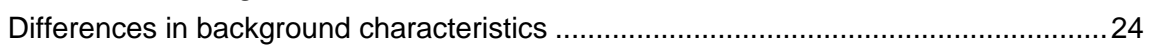

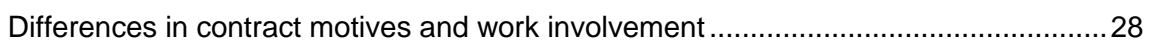

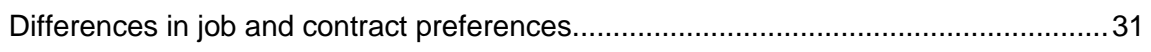

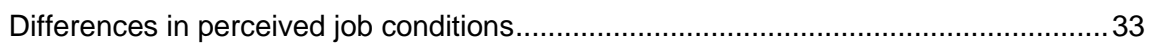

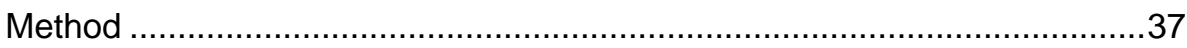

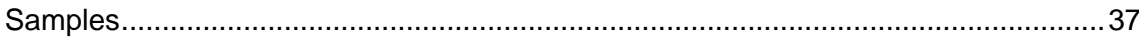

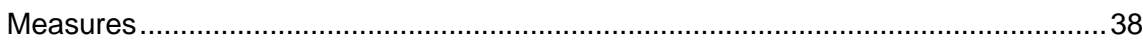

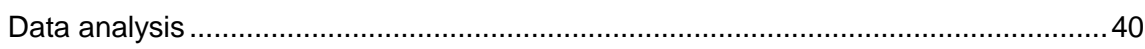

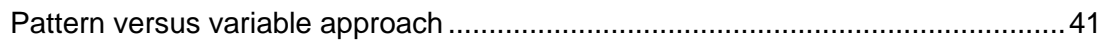

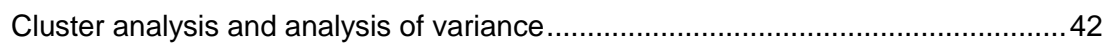

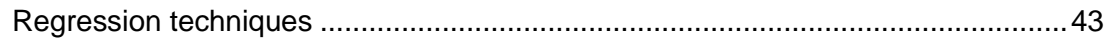

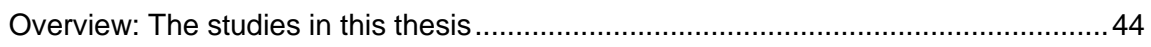

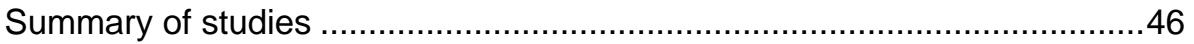

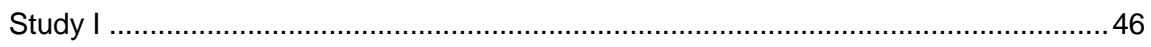

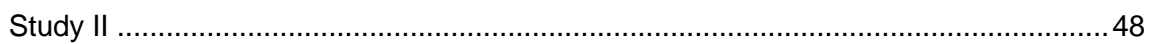




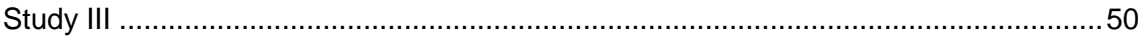

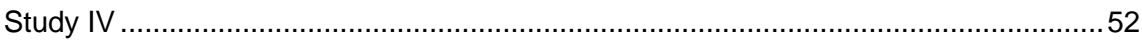

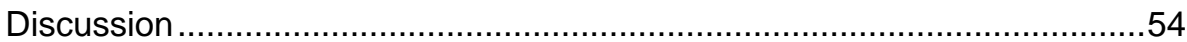

Formal contract and background characteristics ................................................... 54

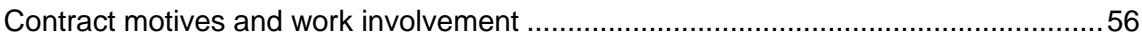

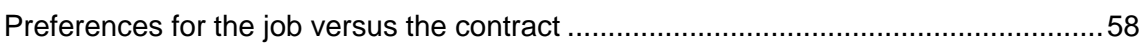

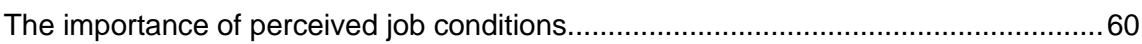

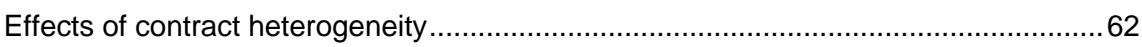

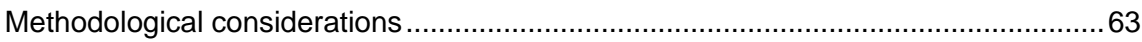

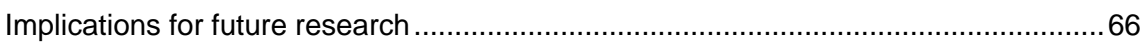

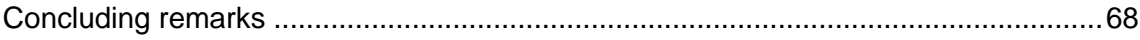

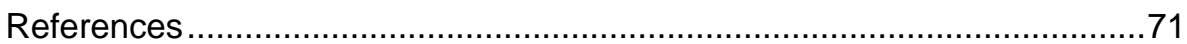




\section{Introduction}

All employment contracts are in a sense temporary obligations, as they take up only a limited part of our time. However, the period of time spent in a certain employment and its daily time demands can differ; the length of one's contract to the same employer, and the hours worked during a day, in other words, can vary. Generally speaking, the employment terms and conditions of a given assignment can be rather heterogeneous today. This development follows a longer period where the industrialized world was characterized by full-time and life-long employment, particularly for male breadwinners, and where other employment forms played a negligible role. Recent decades have witnessed a growing use of 'alternative' employment forms, including non-permanent as well as part-time arrangements. As a consequence, today's workforce finds itself engaged in more divergent and individualized working arrangements, where selling one's labor now involves negotiating over, or simply accepting, a number of potentially quite varying conditions.

For employers, more flexibility is often sought, as organizations seek to acclimate to global markets while minimizing costs, and, to do this, more heterogeneous contractual arrangements are believed to be of benefit and are nowadays a permanent feature in many business strategies (Nollen, 1996). For employees, however, being under contract for a limited time and/or a reduced amount of working hours may lead to more pressure while offering less protection (Burchell, Lapido, \& Wilkinson, 2002). Such an arrangement has been regarded as entailing a shifting of risks from the organizations to the individuals (Beck, 2000), since uncertainties about the continuance and extent of future labor demands have to be dealt with mainly by the individual. Accordingly, it has been strongly conjectured that alternative employment forms constitute stressors for the workforce, which carry with them impaired health and well-being as well as detrimental work-related attitudes (Beard \& Edwards, 1995).

However, simply associating contracts with outcomes may result in a rather incomplete picture. Several scholars have noted that the workforce in alternative employment arrangements is increasingly diverse (De Cuyper et al., 2008; Nollen, 1996), which suggests that individual characteristics and perceptions may play an important role in determining whether the 
consequences of a contractual arrangement turn out to be positive or negative. Although a growing amount of research is directing its attention to the question of how contract conditions and individual differences together relate to outcomes, research in this area is far from synthesized. Thus, to date, the question of whether and in what way alternative employment affects the workforce, and what impact differences among individuals in this workforce have on the results, still remains to be answered. Alternative employment forms play a critical role in contemporary staffing strategies. Their potential impact on individuals may be directly related to long-term workability and productivity (Posthuma, Campion, \& Vargas, 2005), which therefore may lead to economic and societal consequences in the long run (Pfeffer, 2000).

In order to shed some light on how the positive or negative consequences of contractual arrangements may develop, a short overview concerning the emergence of the contemporary working world and the diversity of existing employment contracts is provided below.

\section{A 'new' world of working}

The wide variety of employment forms that have been globally emerging has been collectively referred to by some as the development of a 'new' type of employment contract (Aronsson, 2001). However, from a historic perspective, many of the phenomena occurring in the contemporary working world are not truly new (Allvin, Aronsson, Hagström, Johansson, \& Lundberg, 2006; Nollen, 1996). On the eve of the industrial revolution, workers were under "simple control" (Pfeffer \& Baron, 1988), which basically consisted of the threat of being replaceable. The trades were controlled by guilds, and trainee systems restricted the distribution of qualified tasks to those in a certain craft, which meant that labor market access varied according to skill level. Long-term obligations were not the norm, as craftsmen and day-to-day laborers of the nineteenth century would typically be assigned just one task at a time and get paid by the hour (Pfeffer \& Baron, 1988).

In the beginning of the twentieth century, F.W. Taylor's scientific management ideas - that tasks should be subdivided into management and manual labor, and that each task could be performed in one best way gradually changed the organization of labor (Abrahamson, 1993). Instead of hiring day-to-day laborers, long-term employment became more beneficial since less time and energy needed to be spent on training, which resulted in higher productivity (Nollen \& Axel, 1998). Furthermore, company-specific skills began to be utilized more effectively (Barker \& Christensen, 1998), 
and efforts were also made to get workers to identify with their companies, who hoped that winning workers' trust and loyalty would lead to greater harmony and further positive effects (Cook \& Wall, 1980; Meyer \& Allen, 1997). After World War II, economic growth surged and the demand for labor increased throughout the industrialized world. Later, along with the development of the welfare system in the 1960s and 1970s, a standard of conditions for regular and full-time employment would emerge and become the norm, mainly for the male industrial worker, the breadwinner of the family (Casey \& Alach, 2004; Marler \& Moen, 2005; Menéndez, Benach, Muntaner, Amable, \& O’Campo, 2007). Women's participation in paid labor has grown in the second half of the twentieth century (Casey \& Alach, 2004), but to what degree still differs widely between countries (Ellingsäter \& Ronsen, 1996), as it is a function of differences in values and societal welfare systems (Artazcoz, Borrell, Benach, Cortés, \& Rohlfs, 2004).

From the 1980s onwards, a 'new' world of working has evolved, characterized by the development of more individualized and flexible employment forms. Women are generally overrepresented in such arrangements (European Foundation, 2004), although it has to be noted that males predominate in some of these employment forms, such as project work (Aronsson Gustafsson, \& Dallner, 2002) The pace, magnitude, and spread of this trend of new employment types into all kinds of sectors and occupations has thus been considerable, and may have begun to undermine the previous standard of permanent and full-time work. It is therefore regarded as one of the most fundamental evolutions in contemporary Western working life (Bergström \& Storrie, 2003; De Cuyper et al., 2008).

This development has had several driving forces. One is that many companies have increased their international investments considerably in order to better access foreign markets with new clients (Particelli, 1990). The IT revolution has undoubtedly also played a role (Castells, 1998), facilitating communication and cooperation via the Internet (Roberts, 2000). Political changes have had an influence as well: the fall of the Soviet Union and democratization in the former Eastern Block have led to the opening up of new markets and facilited international trade (Allvin et al., 2006).

Yet another reason behind these changes in the working world relates to national contexts. With governmental regulations and collective agreements becoming less influential in many instances, many companies have become more dependent on global markets, which has made it necessary for them to be able to quickly adjust to fluctuations in the production demands for their goods and services (Pfeffer, 2000). Reducing costs, setting up new ownership structures, and downsizing in order to produce slim organizations (in accordance with principles of lean production) have been common 
strategies for increasing efficiency (Kets deVries \& Balazs, 1997). It has become common today for organizational management to put a greater focus on market orientation (Christensen \& Lagreid, 2000), which has even affected sectors and organizations acting on a regional or national level. Change has also occurred for many traditional non-profit organizations that provide public services, such as schools or hospitals, which have in recent years been transformed into profit-oriented businesses (Ferlie, Ashburner, Fitzgerald, \& Pettigrew, 1996). Altogether, these developments have fundamentally changed how work is organized, leading to a new standard characterized by the need for more flexibility, the externalization of labor, and the increasing individualization of employment relations (Reilly, 1998).

This development was most rapid during the late 1980s and early 1990s (De Cuyper, Isaksson, \& De Witte, 2005), or in the case of Sweden, mainly during the mid-1990s (Holmlund \& Storrie, 2002). The growth of alternative employment has thus occurred during times of economic recession and higher rates of unemployment, which may have limited the willingness of companies to contract on a full-time or open-ended basis (Holmlund \& Storrie, 2002). However, following the improvement of economic circumstances at the turn of the millennium, the use of non-traditional employment forms has not declined to the same degree, which has led many scholars to believe that these employment forms have come to stay, and that they may even continue to increase in proportion, albeit, perhaps, at a more moderate pace (OECD, 2002). In spite of some radical forecasts on the future of work and long-term employment (e.g., Rifkin, 1995), contracts that deviate from the established standard are not the dominant forms of employment today, although they are significant in that they may indicate an overall trend of "things to come" (Guest, 2004, p. 4).

\section{An emerging plethora of employment forms}

As long as the standard of open-ended full-time employment held, the subject of employment contract types has attracted little research attention. However, with the increasing use of many different alternative employment forms, scientific interest in studying and explaining the impact of contract terms on workers' attitudes, behavior, and well-being has grown significantly (De Cuyper et al., 2008).

The increases in part-time work since the 1980s have today resulted in about 18 percent of all workers, the majority of them females, in the European Union holding part-time employment, with somewhat higher percentages in Scandinavia, whereas the use of part-timers has remained low in Southern Europe (Corral \& Isusi, 2004). The growth of part-time work stimulated the first studies on the impact of contract conditions, in which it was questioned 
whether a reduced presence in the workplace had any noticeable effect on the workers' attitudes and behavior (e.g., Eberhardt \& Shani, 1984).

Along with the quick development of telecommunications, working as a telecommuter or teleworker became more widespread in the 1990s (McLean Parks, Kidder, \& Gallagher, 1998). This development has fueled scientific and public discussion on the potential effects of working from a distance or in places not directly controllable by the employer, including research on the disintegration of work-home boundaries (Kylin, 2007).

In addition, many labor law reforms took place in the 1990s, which have liberalized many of the formerly strict regulations applying to temporary agency work and private employment exchanges in many OECD countries (OECD, 1999); in Sweden, for example, such reforms would allow work practices that had previously been considered illegal activities or close to it (Bergström \& Storrie, 2003). These reforms led to the rapid growth of a certain type of agency employment involving a rather specific triangular relationship between employer (the agency), employee, and client (by whom the employee is hired for a given time). For instance, in Scandinavia, Spain and Austria, agency employment increased by at least five-fold (Neugart \& Storrie, 2005). Generally, it may be said that with the liberalization of employment protection legislation in many industrialized countries (Bergström \& Storrie, 2003; OECD, 1999), a common trend towards more temporary contracts set in, and gradually, scientists and practitioners have taken more of an interest in studying its potential consequences.

Employment contracts that deviate from the traditional have been given many different names (Aronsson, 2001), and the choice of terminology may relate to whether the focus lies on the potential advantages or risks connected with the different employment forms. Part-time and temporary work have been collectively referred to, for example, as "atypical employment” (Bardasi \& Francesconi, 2004), or "non-standard employment" (Allan, Brosnan, Horwitz, \& Walsh, 2001), accentuating their divergence from the established or expected standard. Also, the rather inclusive term "alternative work arrangements" (Barling \& Gallagher, 1996) has been used, which stresses the notion that these employment forms represent greater options and opportunities beyond permanent full-time work. Others have chosen a wording that alludes to the view that these types of contracts imply an exposure to an objectively stressful and uncertain employment situation, by calling these contract forms "precarious" (e.g., Menéndez et al., 2007). In contrast to this, the term "flexible" has also found some use (e.g., Reilly, 1998), and tends to evoke more of a positive picture as it highlights the increased leverage that may accompany the use of such contracts, which may not only grant organizations more freedom when 
employing or terminating workers, but also give workers greater opportunity to decide when and how much to work (Allan et al., 2001; Guest, 2004). Similarly, even the terms "free" and "boundaryless" have been used in contexts emphasizing the advantages of flexibility for workers. (Guest, Oakley, Clinton, \& Budchanovcanin, 2006; Marler, Woodard Barringer, \& Milkovich, 2002).

Various terminology has also been used to describe temporary work, e.g., referring to it as "non-permanent employment" (De Cuyper et al., 2008; OECD, 2002), "contingent work” (Connelly \& Gallagher, 2004; McLean Parks et al., 1998) or "casual work" (Wooden, 2001). Concerning the actual spread of temporary work in Europe, it is estimated that about 13 percent of all European workers, a majority of them women, are employed on a temporary basis. However, the figures differ between countries, ranging from 9 percent in Luxembourg to about 38 percent in Spain, while the 13 percent for Sweden is close to the EU average at 15 percent (Goudswaard \& Andries, 2002). Also, variations may exist in the statistics in part because of the diversity of different forms among the countries (McLean Parks et al., 1998), which, moreover, may be defined and classified slightly differently, which further complicates comparisons.

As can be seen in this short overview, there is a plethora of emerging employment forms, and the terminology and classifications used to describe them and study their consequences vary widely, which makes research in this field multifaceted and difficult to synthesize. In this thesis, all employment forms deviating from permanent full-time work are referred to as 'alternative' employment forms, since this terminology makes it possible to embrace both part-time as well as various forms of temporary work. Also, it emphasizes that these forms of employment may be seen as alternatives, which semantically may be regarded as a more neutral term compared to the negative connotations inherent in the wording 'precarious' and the positive connotations in the terms 'flexible' or 'free' work.

\section{Consequences of alternative employment forms}

From the perspective of human resource management, employing workers on part-time or temporary schedules is believed to cut labor costs, and to reduce recruitment costs for short-term positions (Biggs, Burchell, \& Millmore, 2006). Also, it has been said that the size of the workforce can more easily be adjusted to meet fluctuating workloads with such employees (Allan, 2002). While these benefits have been claimed frequently, the extent to which these measures actually make organizations more competitive or cost-effective is rarely studied (Bergström \& Storrie, 2003). 
When looking at alternative employment contracts from the point of view of the employees, a far more critical picture emerges. Here, both research and public discussion have warned against its possible negative effects (De Cuyper et al., 2005), assuming that alternative employment implies impaired working conditions and, thus, imposed risks on the workers' health and safety, or that it might hamper the development of pro-organizational attitudes and behavior. For example, alternative employment forms have been associated with the loss of organizational identification and a sense of marginalization (Guest, 2004), which may have unfavorable consequences on product quality and worker commitment (Bergström \& Storrie, 2003). The fact that individuals with looser ties to an organization typically receive less training on and off the job has been regarded as negative for safety behavior and safety knowledge since there is a potentially higher risk for workplace accidents (Aronsson, 1999; Kochan, Smith, Wells, \& Rebitzer, 1994; Probst \& Brubaker, 2001). Furthermore, the employment uncertainty that may be inherent in alternative employment has also been assumed to lead to impaired well-being and health (Martens, Nijhuis, van Boxtel, \& Knottnerus, 1999; P. Virtanen, Vahtera, Kivimäki, Pentti, \& Ferrie, 2002), or to have a negative impact on organizational behaviors (Chambel \& Castanheira, 2006) or work-related attitudes (Sverke, Hellgren, \& Gallagher 2000). Although the number of research studies concerning these questions is steadily growing, a recent review of the literature has shown that the results in this area are still fairly inconclusive (De Cuyper et al., 2008), which leaves the negative picture presented above largely unconfirmed.

Ever since the first contradictory results emerged concerning the effects of alternative employment forms, a lively debate has been going on about its possible explanations, and researchers seem to agree that the study of alternative employment poses many challenges. Some point to the lack of theories and concepts on the phenomenon (Menéndez et al., 2007), as well as question the suitability of using concepts developed for the study of permanent employment (Connelly \& Gallagher, 2004; De Cuyper et al., 2008). Furthermore, it would seem that some more longitudinal studies may be needed in order to test causal chains and to capture long-term consequences (Aronsson, 2001).

Another and rather often cited explanation for the contradictory findings relates to the fact that alternative employment on the whole implies a variety of contracts that cover a wide range of jobs which are carried out by many different individuals. In other words, alternative employment implies a multifaceted heterogeneity, which needs to be better understood (De Cuyper et al., 2008; M. Virtanen, Kivimäki, Joensuu, Virtanen, Elovainio, \& Vahtera, 2005). 
In regard to employment contracts, criticism has been raised against the dichotomization of permanent versus alternative employment. Many studies on employment status clump all kinds of alternative contract forms together in one group (Aronsson, 2001), which overlooks the differences existing between them. Given that contracts range from day-to-day employment to project employment lasting up to several years, alternative employment forms need to be studied in closer detail in order to increase our knowledge about their potential consequences. Still, a better differentiation of contractual agreements alone may not be enough, since it only captures what employment conditions workers are exposed to. Another challenge for research on alternative employment forms concerns how heterogeneity in contracts is met by diversity in the workforce (De Cuyper et al., 2008). Rather different individuals may be found with different contract types, or even with the same contract type. Thus, the scientific analysis of alternative employment needs to be expanded so that individual consequences can be investigated along a 'psychological' dimension. By capturing how different employment forms are understood, defined, and perceived, it may be possible to better depict how different reactions are evoked from the interplay of heterogeneous contract conditions and individual differences.

A very obvious way of distinguishing individuals is according to their background characteristics. Particularly among temporary workers, age, gender, financial situation, education, and work-related indicators of tenure are known to vary widely (Cohany, Hipple, Nardone, Polivka, \& Stewart, 1998; DiNatale, 2001). Moreover, educational level and occupational background may differ between employees today. The alternative workforce is made up of a variety of types of workers, ranging from those who are highly skilled in a certain field (Bryson \& Blackwell, 2006) to those who have few skills and work in manual jobs (Bryson \& Blackwell, 2006). Although often overlooked, differences in individuals' characteristics may explain the variety of reactions that occur in regard to alternative employment (M. Virtanen, 2003), since the way in which individuals handle their employment conditions may in part depend on their attributes (Endler \& Magnusson, 1976). Because of different demographic attributes, individuals in alternative employment may experience and interpret their contractual agreements in various ways. Therefore, the idea that alternative employment imposes risks or challenges in the same way for all workers, and only because of characteristics inherent in the contract, may be too simplistic. For example, background factors such as age, gender, education, and family situation may associate with generation effects, different work and non-work roles, the dependence on a stable income, or the opportunities to find other employment. Differences in background characteristics may therefore associate with variances in workers' reactions towards alternative employment. 
Differences in background characteristics may also be connected to differences regarding contract motives (de Jong, De Cuyper, De Witte, Silla, \& Bernhard-Oettel, in press; Martin \& Sinclair, 2007; Tan \& Tan, 2002), preferences for job as compared to contract (Aronsson \& Göransson, 1999), and the importance of work in one's life. In fact, it has been suggested that the degree of volition for taking on a certain work arrangement is one of the most powerful sources of variance for explaining inconsistent findings (Connelly \& Gallagher, 2004; De Cuyper et al., 2008; Isaksson \& Bellaagh, 2002; McLean Parks et al., 1998).

Furthermore, while some workers in alternative contract forms may have highly stimulating job tasks (Wikman, Andersson, \& Bastin, 1998), others seem to be engaged in poor quality jobs (Goudswaard \& Andries, 2001; Letourneux, 1998). Also, the length of the job commitment and its inherent time horizon or stability may vary (McLean Parks et al., 1998). In consequence, workers may perceive job characteristics and job insecurity rather differently. Aside from the variety in contractual agreements, perceived job conditions may be another source of variance for explaining why attitudes, behavior, and well-being in the alternative workforce may differ.

In sum, research on the consequences of alternative employment forms, particularly when the focus is on the consequences for the individual, needs to capture the heterogeneity in employment conditions along with the differences in individual backgrounds and perceptions in order to shed more light on the implications of alternative employment for workers.

\section{Research model and aims}

The conceptual research model for this thesis attempts to capture the interplay between contract heterogeneity and the differences between individuals. The model draws on the basic assumptions in interactionist models that relate to organizational contexts (e.g., Katz \& Kahn, 1978). Very generally speaking, such models claim that any positive or negative outcomes depend on how the actual surroundings are experienced or interpreted by individuals. This fits together rather well with the idea that individuals are exposed to heterogeneous contract conditions which are interpreted and perceived differently. How the individual is assumed to fit into the organization, in terms of employment contracts and conditions, is depicted in Figure 1.

According to Figure 1, societal surroundings, including the welfare system and labor law legislation, are thought to have a general impact on both the 
individual and the organization, particularly in regard to the formal terms of the employment contract. With formal employment contracts, individuals and organizations are tied to each other, and due to the heterogeneity in employment contracts, individuals may be exposed to different conditions, depending on the type of contractual agreement signed. Moreover, the organizational circumstances may differ in terms of their structural characteristics (e.g., organizational size, ownership, etc.) and strategies (e.g., the motives for different employment forms and the division and organization of labor).

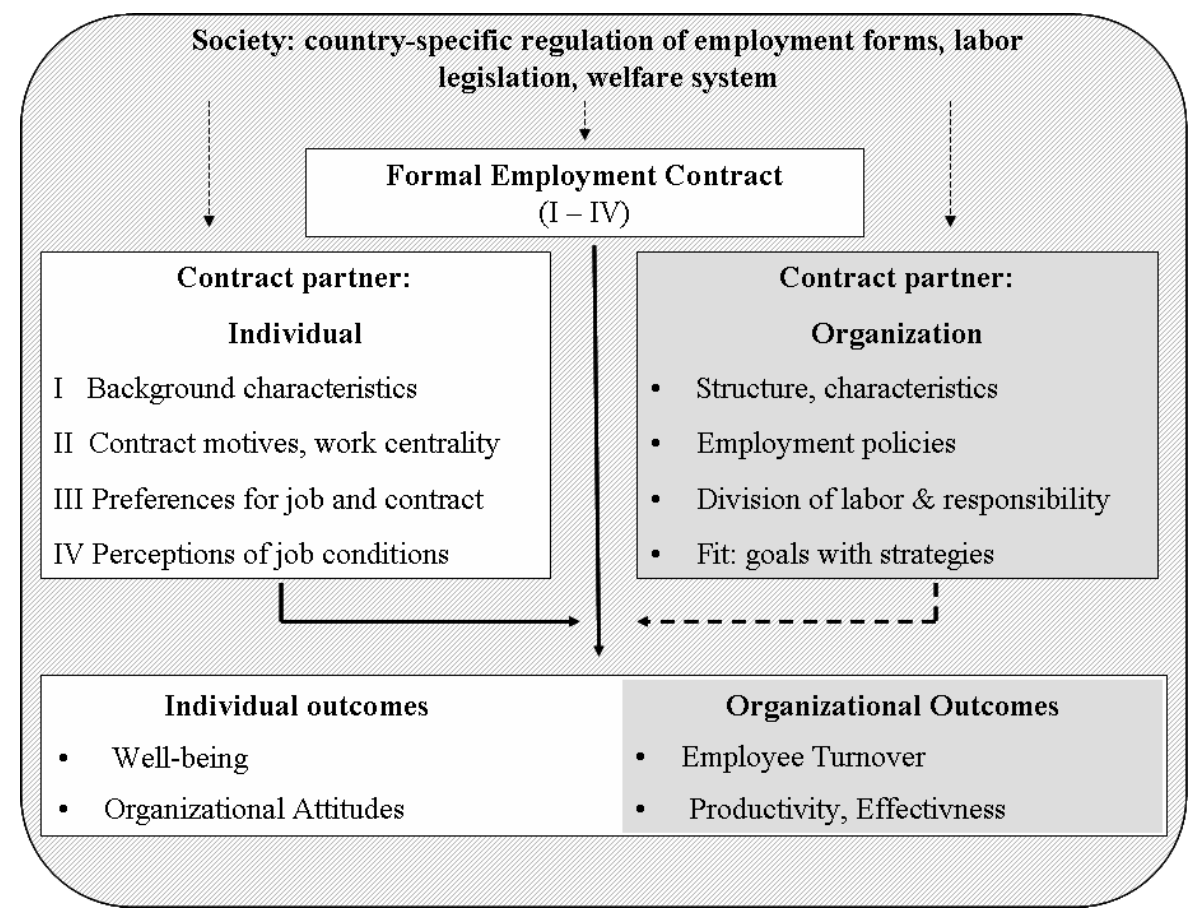

Figure 1. Conceptual and research model (the roman numerals represent the research studies in which these aspects are addressed).

Individuals' exposure to all of these aspects, along with their personal characteristics, are believed to shape their perceptions of how well the employment relationships fulfill their needs and expectations, which results in noticeably positive or negative consequences for both parties. Undoubtedly, it would be interesting to look more closely at the organizational aspects as well as the influences of societal circumstances in order to learn more about individual and organizational outcomes. This thesis, however, is more concerned with the psychological aspects of the 
individual, since the consequences experienced by the workforce are believed to be the most relevant to "make flexibility work" (Reilly, 1998, p. 19). Also, knowledge about individual consequences may be essential for approaching more complex questions of a managerial or sociological character. Areas outside of the scope of this thesis are grayed in Figure 1, and relations that are not studied in this thesis, though they are thought to exist, are illustrated as dotted arrows.

With an emphasis on formal contracts, individual differences, and individual outcomes, the general aim of this thesis is to increase our knowledge about what alternative employment implies for the individual in terms of wellbeing and organizational attitudes. The thesis therefore rests upon the following tenets. Firstly, research on the consequences of alternative employment forms needs to recognize heterogeneity in employment status. Heterogeneous formal contract terms represent different objective employment conditions that individuals are exposed to, and these terms may be associated with different consequences. However, to understand individuals' reactions to their employment conditions, this perspective alone may be too narrow. The second tenet of this thesis therefore calls for the use of a psychological perspective on individual differences. This acknowledges the underlying assumption that individual reactions towards different alternative employment forms are in part shaped by the perceptions and interpretations of the individuals who are employed in these contracts. Together with contract heterogeneity, this thesis also investigates the role of individual differences in order to better understand their consequences in regard to four specific aims.

The first specific aim of this thesis is to analyze the impact of differences in individual backgrounds, together with the aspect of heterogeneity in formal employment contracts, on individual consequences. In accordance with this first aim, Study I investigated whether temporary employees differed with respect to job-related role stressors, work-related attitudes, and well-being indicators, when they were grouped according to their alternative employment forms and their individual background characteristics.

The second aim of this thesis is to study the role of contract motives and work involvement for employee-related outcomes. Corresponding to this aim, Study II investigated whether temporary employees' work-related and general well-being varied as a function of their specific patterns of contract motives and levels of general work involvement.

The third aim of this thesis is to better understand the role of individual job and contract preferences in relation to different contract types and their associated consequences. Accordingly, Study III investigated how type of 
employment contract and subjective preferences for the job as compared to contract related to well-being and organizational attitudes.

The fourth specific aim of this thesis is to study how heterogeneity in employment contracts and individual perceptions of job conditions relate to individual outcomes. Thus, Study IV examined the role of formal employment contract in relation to the effects of job perceptions (demand, control and insecurity) on individual well-being. 


\section{Heterogeneity of formal employment contracts}

To consider formal employment contracts as a heterogeneous phenomenon, in accordance with the first tenet of this thesis, it will be necessary to differentiate them beyond the mere dichotomous classification into permanent and temporary contracts. But just how can different employment contracts be conceptualized, and systematized? In this chapter, different frameworks for capturing the differences in employment status are discussed and compared. Furthermore, the employment contracts that are central to this thesis are characterized, and their potential implications for individual outcomes in terms of health, well-being, and organizational attitudes are discussed.

\section{The concept of employment status in different frameworks}

The conceptualization as well as differentiation of various types of employment contracts has mainly been based on the notions that different contractual agreements associate with different possibilities of entering and advancing in the labor market (Doeringer \& Piore, 1971), and that the relation between stability and temporality in regard to the contract associates with different levels of security and organizational attachment for employees, which lands them either at the core of a company or in a more peripheral position (Aronsson, 2001; Atkinson, 1984). Furthermore, differences between contracts have been discussed in terms of the degree of social inclusion they may provide within organizational life (Thorsteinson, 2003) or in terms of their structural characteristics (for an overview, see De Cuyper et al., 2008).

\section{Dual labor market theory and flexible firm model}

The framework of the flexible firm (Atkinson, 1984) and the dual labor market theory (Doeringer \& Piore, 1971) are two fundamental models referred to in the majority of research on employment contracts (De Cuyper et al., 2008). Doeringer and Piore's (1971) model takes a labor market 
perspective, while the model suggested by Atkinson (1984) primarily concerns the distribution of (internal) labor in an organization. Common to both models is that permanent full-time arrangements with a single employer, either in the primary sector of the labor market or at the core of a company, are considered to be the standard around which all the other forms are grouped. Permanent full-time workers within this standard are provided with a relatively high employment security and, in exchange, they provide functional flexibility for the company by being available to work on various tasks (Atkinson, 1984). Workers in the secondary labor market, on the other hand, are regarded as holding highly uncertain employment, with few opportunities for advancement or movement into the primary sector (Doeringer \& Piore, 1971). This secondary or alternative employment can take many forms, and guarantees several types of flexibility for organizations, as those with such contracts are mainly used to substitute or supplement the core workforce in the primary labor market. Some researchers (e.g., Reilly, 1998) have divided the flexibility that these forms provide for the employer into two main categories: temporal flexibility, involving restrictions on working time (e.g., with part-time work); and numerical flexibility, where restrictions pertain to the length of employment (e.g., with temporary work), which facilitates varying the number of employees.

Beyond this conceptualization of a dual labor market, the other model, the flexible firm model, makes a further differentiation between dependent employees by distinguishing between those of the primary and secondary segment who hold jobs with specific companies and those of a third group who work outside of companies. This third or tertiary group is not under the administrative control of the company (Pfeffer \& Baron, 1988). It can thus be described as a rather marginal group with very loose ties to the organization. The types of jobs that are resourced from outside the company are often very specialized (e.g., IT-solutions) or mundane (e.g., office cleaning), and their contracts typically take the forms of self-employed workers, sub-contractors, or temporary agency workers (Atkinson, 1984).

Neither of these models has escaped criticism with much of it being directed at the way in which the primary and secondary labor markets are broadly differentiated along the lines of insiders and outsiders - which may overlook the complexity existing between these groups (De Cuyper et al., 2008; Saloniemi, Virtanen, \& Vahtera, 2004).

\section{Employment status in a core-periphery structure}

Instead of ordering employment forms into two or three categories, recent research has set forth the idea of using a more refined core-periphery 
structure in which employment contract is placed along a continuum (Aronsson et al., 2002; P. Virtanen, Liukkonen, Vahtera, Kivimäki, \& Koskenvuo, 2003). More 'core' types of employment imply a closer connection to the organization, while more 'peripheral' types of employment have looser ties, all according to a number of factors. At the core end of the continuum is permanent full-time employment, followed by gradually more peripheral types, such as permanent part-time work and temporary work (see Aronsson et al., 2002), then governmental subsidized employment (P. Virtanen et al., 2002), and finally unemployment at the peripheral end (Dooley, 2003). With permanent full-time employment as the standard of comparison, the placement of the other employment forms along the coreperiphery axis depends on what their conditions are in relation to a number of core-related features, including the safety net, employment security, status control, training, and development (Aronsson et al., 2002; M. Virtanen, Kivimäki, Joenssu, et al., 2005). These features, which mainly refer to security and benefits, are distributed differently among those of the periphery, and typically, the shorter the length of a contract, the more dissimilar, and thus peripheral the employment (Aronsson et al., 2002; M. Virtanen, 2003). For example, according to the core-periphery structure, an employee working for a probationary period, which often leads to a permanent contract, would be in a type of employment that would be placed closer to the core end than, say, employment in which someone has a shortterm contract, such as with daily or on-call work on short notice (Aronsson et al., 2002). Rather than being limited to broadly classifying the temporary contract types into the secondary or tertiary labor markets, as with the flexible firm model and the dual labor market framework, the core-periphery structuring, in which these types can be sorted along the periphery, allows for greater differentiation.

In accordance with the above-described core-periphery continuum alternative employment types may be ordered along the periphery according to their degree of employment security and benefits provided (M. Virtanen, Kivimäki, Joenssu, et al., 2005; P. Virtanen et al., 2003). However, it may be questioned whether such a one-to-one correspondence indeed can be established or whether the ranking of employment forms may depend too much upon which features are considered to be representative of typical core features. In fact, alternative employment rather seems to be a multidimensional construct (Menéndez et al., 2007) that may be defined by dimensions such as temporality (M. Virtanen, Kivimäki, Joenssu, et al., 2005), but also powerlessness, or even degree of inclusion in the organization (Thorsteinson, 2003). Also, to order contracts according to these features may not be as unequivocal as it seems. For example, at first glance, an on-call contract may be considered more peripheral than fixedterm work (Aronsson et al., 2002). However, it may be questioned whether 
an on-call worker who is registered in a pool would experience more or less uncertainty than someone on a fixed-term contract that will be ending in the near future. Furthermore, this conceptualization seems to overlook the dynamics of repeated temporary work, including the fact that working in different organizations may lead to the building of networks and the development of meta-skills (De Cuyper et al., 2008), as well as open the door for more core and stable employment in the long run (Gagliarducci, 2005). When comparing employment forms in terms of the degree of inclusion in organizational life they offer, one may argue that employment that asks for attendance in the workplace on a part-time but permanent basis - which should place it near the core end of the continuum - in fact occasions more exclusion and less of a sense of belonging than a full-time schedule in a project or substitute work over a long time would. Also, in terms of power, empirical studies on factors such as decision influence and expressing voice have not established a clear core-periphery ranking of employment forms (see, e.g., Aronsson \& Gustafsson, 1999)

Thus, although it goes beyond the simple duality of the dual labor market conceptualization, a strict core-periphery ordering, in which each employment form can be placed closer or farther from the 'ideal' of permanent full-time employment, seems to be hampered by the fact that alternative employment forms may be ordered differently depending upon which underlying criteria the ordering is based on.

\section{The qualitatively different conditions of employment contracts}

Instead of ordering different types of employment statuses along a single continuum, employment forms may be conceptually distinguished according to a number of structural characteristics. Regarding these structural characteristics, many researchers agree that employment can be differentiated on the basis of contract duration, the amount and scheduling of working time (Hoffmann \& Walwei, 1998; Martens et al., 1999), the involvement of a third party in terms of clients (McLean Parks et al., 1998), the number of employers worked for simultaneously (Gallagher \& McLean Parks, 2001), the place where work is performed (De Cuyper et al., 2008; Peffer \& Baron, 1988), and the agreements made with respect to payment and fringe benefits (Cohany et al., 1998). With this type of approach, the differences between employment forms are not used to rank or order them, for example, from most secure to most uncertain, and it is not implied that the 'distance' to permanent full-time work can be estimated in any quantitative way. Instead, these structural characteristics are used to describe employment forms in terms of their different qualities. One important difference is that those contract types that were otherwise usually placed in the periphery are, in this approach, disentangled from each other and 
evaluated instead according to their unique combinations of structural characteristics. No distances or rank-orders are thereby assigned among them or in relation to permanent full-time work.

In such a conceptualization the rather heterogeneous nature of alternative employment contracts is emphasized. Such careful differentiation is seen as a necessary step in acquiring a better understanding of their implications for workers. To illustrate, in a rather inclusive overview, McLean Parks et al. (1998) described how various categories of contingent work could be differentiated. Among the main groups they identified were a group which provided the organization with flexibility, known as 'floats,' who would be available to work in all kinds of jobs within an organization, and another, called the 'networked' group, who could work even from remote locations, such as from home as teleworkers. Both of these forms deviate from the standard only slightly and in terms of workplace flexibility, which is believed to be mainly beneficial for the employer. McLean Parks et al. (1998) furthermore described several groups of employees who would be directly hired by the organization, although only for temporary positions, such as seasonal employees, in-house and on-call temporaries, and substitutes for absent permanent workers. Another group included leased workers who, unlike members of the other groups, had not been directly hired. This is a key distinction conceptually, since instead of the classical two-part relationship, there is a triangular relationship between the employer, the employee, and the client organization, affecting where and for whom the employee carries out the work. Also among this group are those employed through temporary agencies. Finally, another no less important group distinguished by McLean Parks et al. (1998) consisted of the self-employed, consultants, and subcontracted workers, who share the characteristic that their work is not directly controlled by the organization. As can be seen, although McLean Parks et al. (1998) suggested four broad groups, there are still remarkable differences within each group. For example, within the group of directly hired workers, employment conditions may still vary, depending on whether the contract is for a whole season, on a (continuous) at-need basis, or for a longer ongoing period in order to substitute for a permanent employee. Nevertheless, by McLean Parks et al.'s (1998) describing and comparing of the characteristics and qualities of employment types, instead of ranking them along a single dimension or a continuum, a more useful categorization has been produced which demonstrates just how different employment conditions can be.

This thesis adopts the view that employment contracts cannot be ordered according to one criterion since they contain a number of varying structural characteristics that form a multi-dimensional whole, relating to payment, continuity of employment, benefits, distribution and number of working 
hours, and where work is performed, etc. These qualitative differences between employment forms are believed to generate objectively different conditions that the workers are 'exposed' to or employed under, which, in this thesis, is considered to be one important reason for expecting varying individual reactions.

\section{The employment forms differentiated in this thesis}

In this thesis the alternative employment forms of permanent part-time and temporary work are investigated, in which the latter is further differentiated into short-term temporary contracts for on-call work and long-term temporary contracts for fixed-term work. Generally, 'fixed-term' and 'oncall workers' are referred to as temporary or contingent employees, and the terms 'contract,' 'arrangement,' 'employment form,' 'employment' and 'assignment' are used interchangeably in the present thesis.

The choice to include some and exclude other alternative employment forms for analysis and comparison with permanent full-time work has been made for several reasons. First, based on the research model presented in the opening chapter of this thesis, it was considered important to keep within the same societal context while studying the variations in employment contracts and the individuals working under them. Accordingly, the employment forms studied in this thesis are all to be found within the national and legislative context of the Swedish labor law regulations and welfare system. Second, it was considered important to keep within those employment settings that had comparable organizational ties, which is why only those alternative employment forms which were found within a single organizational context (as is the case with permanent full-time work), involving a two-part relation between employee and employer, were included. Although other alternative employment forms, such as those with triangular relationships (e.g., leased workers), forms of self-employment, and subcontracting, may also constitute important employment options in contemporary working life, they imply other types of employee-employer relationships - whose study falls beyond the scope of this thesis.

Third, it was also the intention of this thesis to concentrate on the alternative employment forms that are most commonly used in Sweden, and perhaps even in Europe. In choosing to study permanent part-time work and temporary work in the forms of fixed-term and on-call contracts, it was not only important that they involved two-part relations, but that they also were of the types that provided different sorts of flexibility in respect to quantity of time by restricting the number of working hours and/or the length of contracts. Analyses of these different alternative employment forms should 
therefore provide useful information about if and how differences in these employment forms relate to outcomes reported by the workers in regard to their well-being and attitudes.

In the following, the specific characteristics of each of the employment contracts that are central to this thesis are briefly presented, before discussing the documented research results regarding the consequences associated with these contracts and how they can be attributed to contract conditions.

\section{Permanent full-time employment}

The traditional or standard employment relationship is characterized by permanency, offering continuance and the prospect of an open-ended if not even life-long employment (Aronsson, 2001). Thus, it formally provides the employee with a high level of employment security, as well as typically providing workers with full access to benefits, insurance, and other entitlements such as minimum wages, or paid leave. In some places, these types of benefits may not be extended to those with alternative employment, particularly in the US, whereas European employment regulations are rather protective, guaranteeing a minimum level of rights for all employees (De Cuyper et al., 2008). Permanent full-time workers have a high presence in organizations with respect to the hours they spend at work per week, as well as the long-term commitment implied in their ongoing employment contracts. Since they constitute the core of the company, often having worked for many years in their organization, permanent full-timers are valuable human capital for employers and are therefore believed to be in a relatively strong position (Aronsson, 2001; Pfeffer, 2000). Furthermore, permanent workers typically are unionized to a higher degree (Kjellberg, 2001), which can be assumed to strengthen their representation and chances of getting their voice heard. In turn, this is believed to enhance their ability to influence their own work conditions, thus resulting in positive attitudes towards the organization and improved well-being.

Given this and the prospect of continued employment, and thus income, permanent full-time employees would be expected to express high levels of commitment and job satisfaction, and to also have the most favorable reports on well-being among all employment groups.

\section{Permanent part-time employment}

Part-time work refers to employment in which the normal working hours are less than those of a comparable full-time worker. Whereas earlier definitions used to set the maximum at 30 to 35 working hours for part-time 
employment (Barling \& Gallagher, 1996), more recent conceptualizations include references to 'comparable' full-time workers, thereby acknowledging the fact that the 'normal' number of working hours per week can vary considerably across different occupational settings (Corral \& Isusi, 2004). In Europe, part-timers are rather often provided with contract permanency (Krausz, Sagie, \& Bidermann, 2000), while they usually work on fairly fixed and ongoing schedules for the organization. Because of this, part-time employment has previously been conceptualized as a core employment (McLean Parks et al., 1998) or as an employment that is situated closer to the core of a company than temporary contracts (Barling \& Gallagher, 1996).

Thus, part-time work often provides continuance in terms of contract length and regularity of schedules, but results in a reduced presence in the work place due to the (reduced) amount of hours worked. Potential associations between contract conditions and differences in the attitudes, well-being, and behavior of part-timers are therefore frequently linked to the fact that parttimers are present in the organization to a limited extent (Alexandrov, Babakus, \& Yavas, 2007; Thorsteinson, 2003). This lower presence of parttimers and the diminished organizational inclusion carried with it is believed to lead to communication problems, weaker social relationships at work (e.g., Feldman, 1995), and reduced participation in decision-making (Guest et al., 2006). Part-time work also seems to limit employees' promotion and training opportunities (Corral \& Isusi, 2004), which may be explained by the fact that part-timers, compared to full-timers, are believed to be more strongly involved in life-roles outside the organization (Thorsteinson, 2003). Due to weaker organizational ties, part-timers may be more likely to switch employers and find work elsewhere (Alexandrov et al., 2007; Martin \& Sinclair, 2007). However, research findings comparing part-time and fulltime employees have been inconsistent (for a review, see Barling \& Gallagher, 1996), reporting either no differences in job-related attitudes (Krausz et al., 2000), or more positive attitudes for part-time workers (Bardasi \& Francesconi, 2004; Conway \& Briner, 2002; Guest et al., 2006; Martin \& Sinclair, 2007). Some researchers have attributed the finding of more positive attitudes to the notion that even partial inclusion may also carry advantages. For example, while such partial inclusion may lead to parttimers being less involved in organizational life than permanent full-time employees and therefore more prone to missing relevant information, it may at the same time have the beneficial effect of rendering them less exposed to negative events and politics (Thorsteinson, 2003). 


\section{Temporary fixed-term employment}

Temporary fixed-term work is one of the most common forms of temporary employment (OECD, 2002). In Sweden, temporary workers mainly are employed as fixed-term workers substituting for permanent employees on long-term leave (such as sick leave or maternity leave), as project workers, or as probationary employees who are seeking permanent employment with a company. In many cases these types of employment involve being employed under rather long-term contracts, which may be renewable several, although not infinite, times (Bernhard-Oettel \& Isaksson, 2005).

From a theoretical point of view, temporary work, in general, has been assumed to produce unfavorable attitudes and impaired well-being because of its implied association with insecure employment (Näswall \& De Witte, 2003) and, particularly in a non-European context, the disadvantages it may entail regarding pay and access to benefits (OECD, 2002). The discussion on to what extent limited contract duration can also lead to partial exclusion has also been less than positive. It has, for example, frequently been found that temporary workers tend to receive fewer training opportunities and to report less involvement in decision making than permanent workers (Aronsson, 2001; OECD; 2002). Furthermore, non-permanent employment has been found to be a potential hindrance for the planning of long-term goals and commitments, as with career planning (M. Virtanen, Kivimäki, Virtanen, Elovainio, \& Vahtera, 2003).

Seen in this light, the employment conditions of fixed-term work have been presented as less favorable than those of permanent employment, and the often referred to notions of precariousness, uncertainty, and exclusion have parented the assumption that temporary fixed-term work is associated with ill-health (Benach, Benavides, Platt, Diez-Roux, \& Muntaner, 2000). In a representative Swedish study, fixed-term workers, particularly those who were employed as substitutes or on projects, reported less favorable wellbeing than permanent workers (Aronsson et al., 2002). Another recent study reported that temporaries were more likely than permanent full-timers to use antidepressant medication (M. Virtanen et al., 2008). In a meta-analytic review on temporary employment and health, it has been suggested that temporary employment may be associated with increased psychological morbidity (M. Virtanen, Kivimäki, Joenssu, et al., 2005). However, both studies noted that these associations were stronger with more instable types of temporary work. Other studies have not reported evidence of impaired health effects for fixed-term workers, finding, rather, that this group of temporaries exhibited health effects similar to those of permanent employees (Bardasi \& Francesconi, 2004; P. Virtanen et al., 2002). Generally, it has to 
be noted that, as of yet, few studies on this topic have endeavored to differentiate between the various types of temporary employment forms.

Just how the employment conditions of fixed-term workers relate to health, as compared to those of permanent workers, is therefore still unclear. What can be concluded is that the findings underscore the importance of distinguishing between the different forms of temporary employment. From the little evidence provided so far, it appears that engaging in steadier forms of temporary employment, in which there is a regular presence in the workplace over a limited period of time, such as with fixed-term contract work, may occasion a higher degree of inclusion in the organization as well as produce more favorable attitudes and well-being than would occur with certain short-term employment forms such as, for example, on-call or dayto-day work.

\section{Temporary on-call employment}

On-call contracts are to be found within the temporary workforces of many countries, including the US, the Netherlands, Korea (OECD, 2002), and Sweden (see Bernhard-Oettel \& Isaksson, 2005). On-call arrangements are utilized by organizations to fulfill their more immediately emerging staffing needs. Frequently, on-call workers are hired on an as-needed, short-term basis that may only extend over several hours or days (OECD, 2002). Since such workers are often called upon to work on occasions when extra help is required, their working hours tend to be irregular, including nights, holidays, or weekends. These conditions naturally grant a rather limited degree of organizational presence and leave little opportunity for contact with the rest of the staff and supervisors.

Concerning the implications that on-call contracts might have for workers' reactions, research has generally found them to be precarious in nature; in other words, a high degree of uncertainty has often connected with this employment form due to its unreliability, fairly low wage levels, and low degree of contact with the workplace. Consequently, predominantly negative reactions in terms of attitudes and well-being have been expected (Aronsson, Dallner, Lindh, \& Göransson, 2005). In contrast, on-call work may be viewed more positively, by looking at it as a 'free' or 'flexible' contract form, in that it demands only a minimum level of commitment to the organization (Guest, 2004) and gives workers the option to decide on a caseby-case basis how much and when to work.

The empirical evidence on how on-call work, as a particular form of temporary employment, is related to potential outcomes is scarce. One Swedish study, however, has found that on-call workers report having fewer 
opportunities to exert influence and undergo development, as well as more back and neck pain, than permanent and other temporary employees (Aronsson et al., 2002). In another recent study, findings showed that the risk of ill-health increased for those on-call employees who worried about their finances or were in financial difficulties (Aronsson et al., 2005). In regard to two other recent studies that differentiated between fixed-term employment forms and casual, seasonal, and atypical employment and which also included on-call contracts, one found that depression and disease-related symptoms were more common among those who worked with marginal employment contracts (P. Virtanen et al., 2003), while the other found no adverse health effects with these contracts (Bardasi \& Francesconi, 2004).

\section{Concluding notes}

The amount of research concerning the effects of employment status has grown considerably over recent years. However, it is only recently that studies have begun to move beyond the dichotomous categorization of permanent versus alternative employment. While there seems to be some consensus that the heterogeneity of contract conditions matters, the exact implications of employment conditions on individual outcomes still remain difficult to grasp. Furthermore, previous results are difficult to synthesize, since the different employment contracts are studied within various national contexts and across different time periods, which may imply differences in their surrounding conditions, for example, relating to legislative or economic developments. What much of the research on alternative employment forms does have in common is that it often relates or compares contractual arrangements to the 'standard' of permanent full-time work. The majority of research has also taken the perspective that alternative employment forms, in one way or another, lead to precariousness and exclusion, and they are thereby often expected to predominantly entail negative consequences for the workforce. However, only comparing employment forms in terms of what they expose individuals to does not provide any insight into how employment conditions are interpreted and thus experienced by the contract holders. In this regard, differences among individuals working in alternative employment forms may have to be taken into account, since they constitute factors that might influence what working in part-time, short-term, or uncertain arrangements may mean for an employee. 


\section{Differences among individuals}

The second tenet of this thesis is based on the assumption that just disentangling the heterogeneity of employment contracts may not be sufficient for understanding individual reactions. Rather, a necessary extension of earlier research may be to direct more scientific attention to the interplay between contract conditions and the diversity of the individuals working in these contracts. In the following, a number of potentially important aspects that differ among individuals are presented, and their implications for individuals' outcomes are discussed. The aspects considered correspond to the four specific aims of the thesis, namely to generate more knowledge about how formal employment contracts and (1) individual background characteristics, (2) contract motives and work involvement (3) job and contract preferences and (4) perceptions of job conditions explain individuals' reactions in terms of well-being and organizational attitudes.

\section{Differences in background characteristics}

Workers in alternative employment forms differ from other workers in regard to several important characteristics (Cohany et al., 1998). Also, with the growing heterogeneity of employment arrangements, the differences among workers in alternative employment have grown considerable (Wikman et al., 1998). Overall, diversity in the alternative employment workforce has been grounded in differences in socio-demographic factors, such as age, gender, and family situation, as well as in work-demographic factors, such as occupational position, organizational tenure, and work status.

With permanent full-time workers as the comparison group, part-timers and temporary workers have frequently been described as younger, less educated (Nollen, 1996), and disproportionately female (Corral \& Isusi, 2004), and as being in low-wage clerical or administrative jobs in the retail or service industries (Barling \& Gallagher, 1996), or in manual labor (Nollen, 1996). Alternative employment can thus be regarded as a type of work that is more common among low-status groups (Cohany et al., 1998) who have weaker positions in the labor market (Wikman, 2002). Although this characterization may still apply to the majority of the alternative workforce, in recent years, a 
more diverse picture has emerged, highlighting that, in fact, there are also huge differences among those working under alternative contracts, particularly with respect to age, education, occupation, gender, familyrelated background, race, and nationality (Di Natale, 2001; Håkansson, 2001).

Regarding age, it has been noted that alternative employment is most common among young workers who are at the beginning of their occupational careers (European Foundation, 1996; Corral \& Isusi, 2004). Moreover, alternative employment has also been found to be more common among older workers as compared to the middle-aged groups (Håkansson, 2001). The age groups of the younger and the older are comprised of individuals who are either entering or withdrawing from the labor market, which suggests that alternative contracts may be useful for facilitating such transitions.

In terms of education, the percentages of individuals with below-average educational levels (uncompleted high school education) and with aboveaverage educational levels (college degree) have been reported to be higher among workers in alternative employment forms than among permanent fulltime workers (Cohany et al., 1998). These disparities can be viewed in connection with the wide range of occupations that utilize alternative employment contracts today. Part-timers are frequently employed in clerical or menial work, as sales personnel, or in catering, cultural or personal services, and they can also be employed for manual tasks (as blue-collar workers) in the manufacturing industries (Bergström, 2002; Corral \& Isusi, 2004; Holmlund \& Storrie, 2002). Moreover, part-time and temporary employment is becoming more usual even for specialists and other knowledge workers, such as health care professionals (see, e.g. Sverke et al., 2000), IT and business consultants (Guest, 2004), and teachers in higher education (Bryson \& Blackwell, 2006).

Oftentimes, workers in alternative employment forms work shorter working hours than their colleagues on permanent full-time schedules (Corral \& Isusi, 2004; OECD, 2002). However, large differences are found between the different types of employment: on-call workers commonly work the fewest number of hours, whereas, for instance, those in probationary employment are usually on full-time schedules (Håkansson, 2001). Also, the scheduling and regularity of working hours may vary according to when the employer needs extra personnel to work, which may be during unusual working hours or at those times when the core staff is reduced, e.g., during nights, evenings, and weekends. A Belgian study, for example, reported that a majority of the temporary workers had flexible working schedules that called for irregular 
hours, compressed working weeks, and continuous hours in shifts including nights and weekends (Martens et al., 1999).

When it comes to gender, far more women have been reported to work in part-time jobs or as temporary employees than men (Corral \& Isusi, 2004; Wikman, 2002), which is believed to mirror the fact that women, more than men, seek to combine their work life with family-related and domestic obligations (Marler \& Moen, 2005). Men in alternative employment, however, are more likely to transition into core, full-time employment than their female counterparts (OECD 1999). Another difference is that more men than women are found in those temporary employment forms which involve longer tenure and thus higher employment stability (Wikman et al., 1998). Besides these gender-related differences and the others mentioned above, other types of background characteristics have been found to relate to alternative employment: in particular, it is important to note that workers with immigrant backgrounds and, especially in the US, non-whites tend to be overrepresented in alternative employment forms (Cohany et al., 1998; Wikman, 2002).

Whereas associations between alternative employment forms and background characteristics have been documented carefully in earlier research (OECD, 2002; Wikman et al., 1998), the impact of individual and work-related background characteristics on consequences has rarely been studied. To be sure, background variables remain important in this regard, since they refer to attributes that differentiate individuals and their specific working circumstances and experiences. In line with the interactionist perspective presented in the research model in the introduction, employees' reactions, such as attitudes and reports on well-being, are assumed to have the potential of being affected by the interplay between their attributes and characteristics of the environment (Endler \& Magnusson, 1976) including, in the present case, the conditions of the specific contract forms. Thus, individuals with different attributes, who are employed under the same specific type of contract, may differ in respect to their needs and expectations, and likewise, individuals with similar attributes, but with different employment and work conditions, may perceive their situation rather differently from each other. Accordingly, differences in attitudes, well-being, and health variables can be expected to result from the interplay between individuals' work-related and personal attributes and their employment forms. This has been documented, for example, in findings where those who both worked irregular hours, which may be more common in some occupations and sectors than in others, and had uncertain employment situations reported more health complaints, irrespective of certain personal background characteristics, such as age and education (Martens et al., 1999). Such a relationship may also be witnessed in the 
differences between younger and older newcomers to an organization; while younger newcomers may be likely to undergo a period of strain in the beginning as they learn the ropes (Sverke et al., 2000), older workers, in comparison to those first entering the labor market, would be likelier to have acquired more general work experience and portable skills already, and may therefore have values and expectations that differ from those of the younger generation (Loughlin \& Barling, 2001) and thus, adjustment processes and job transitions may differ between these groups.

Personal background factors, such as family situation and having children to provide for, may be factors that also associate with consequences of alternative employment. Marital status has consistently been found to relate positively to well-being (Diener, Suh, Lucas, \& Smith, 1999), which may be explained by the fact that partners can be a source of social as well as economic support. Indeed, those in alternative employment who highly depend on having a steady income, such as lone income earners with kids or other family members to provide for, seem to report higher levels of strain and health problems, particularly when their employment is short term and prone to frequent job changes (Aronsson et al., 2005; Buttram, 1996).

In recent research highlighting the role of gender, it has been suggested that the consequences related to alternative employment may in fact differ between men and women (Marler \& Moen, 2005). A gendered division of labor often means that women carry the greater burden of household responsibilities, and in regard to alternative employment forms in particular, the unpredictability of working schedules (e.g., in on-call work) has been assumed to lead to adverse effects on women's mental health, instead of better work-family balances (Meréndez et al., 2007).

In a number of studies, particularly in early reports on the consequences of alternative employment, the impact of individual background differences has often been overlooked (M. Virtanen, 2003). In recent research, socio- and work-related demographics have mostly been dealt with by controlling for their effect, since they may change how employment contracts relate to outcomes (Bardasi \& Francesconi, 2004). Little focus has been put on the direct relationships between individuals' backgrounds and their work-related attitudes and well-being. In other words, we know little about how much the heterogeneity in the backgrounds of workers in alternative employment actually explains their diverse reactions towards their work. Many of the above-discussed factors, however, may be interrelated. For example, young age, unfinished school education, and little work experience often seem to be characteristic for high schoolers working as part-timers or temporaries. Another example concerns those who work in the service sector, as they are typically lower-educated, female, and often only hired to work for a reduced 
amount of hours or for a short time, such as during the summer season. Given this, it is quite possible that low pay and unstable work are interrelated with gender and education. However, what the combined effect of these factors could be has rarely been investigated.

\section{Differences in contract motives and work involvement}

Along with their demographics, which reflects a large range of diverse social and economical characteristics, and their heterogeneous work biographies, individuals also differ on their reasons for taking on alternative employment. Very generally, their motives may be considered either voluntary or involuntary in nature (Tan \& Tan, 2002), depending on their perceived degree of choice in the matter, and will be referred to in the following as 'voluntary' motives and ‘involuntary' motives respectively.

Voluntary motives for working under a temporary or part-time contract can be rather heterogeneous, but all of them are rooted in the advantages that can be gained in flexibility for the employee. The voluntary reasons that relate to family matters, for instance, have been found to focus on the notion that flexible or shortened time schedules may be advantageous in that they facilitate the organization of child care or other family obligations (Tan \& Tan, 2002). Some researchers suggest that this might be particularly attractive for working women (Nollen, 1996). Empirical data from the US Population Survey, however, found that only one out of four women cited such flexibility related reasons (Morris \& Vekker, 2001). Besides flexibility, temporary work or part-time employment may be chosen in order to provide extra income, for example, when a non-breadwinner in a family takes on the work in order to supplement the family's income (Tan \& Tan, 2002). In some cases, temporary work is even known to be better paying than comparable permanent work (e.g., when organizations hire in specialists) and then, it may be chosen to increase wages (Morris \& Vekker, 2001). Individuals entering the labor market for the first time, particularly high schoolers, college students, and those who recently completed their education, seem to choose alternative employment while they are in school or undergoing training (Bernasek \& Kinnear, 1999; DiNatale, 2001). This is generally done in order to gain work experience in different organizations, or to improve their skills and expand their resumé (Nollen, 1996; Tan \& Tan, 2002). Finally, some individuals may express a personal preference for temporary work that is motivated by a dislike for the degree of commitment that permanent employment entails (Guest, 2004).

In general, however, predominantly voluntary motives are only given by one out of every three temporary workers, according to labor statistics from the 
US and Europe (Guest, 2004). Part-time work is chosen voluntarily to a higher degree among working parents (Gaspirani, 2000; OECD, 1999). However, statistics indicate that the increase in part-time work during the last years mainly is an involuntary one (OECD, 1999).

Involuntary reasons for alternative employment relate to circumstances in which individuals accept alternative employment forms due to lack of other, more permanent (Morris \& Vekker, 2001) or full-time alternatives (OECD, 1999). Several empirical studies in Europe and North America reveal that a majority of temporary workers, and a growing percentage of part-timers, accept their employment mainly on involuntary grounds (Corral \& Isusi; 2004; De Cuyper et al., 2005; OECD, 1999). There are several main reasons why workers in these circumstances usually feel compelled to accept whatever assignment there is: they may wish to avoid unemployment (Bellaagh \& Isaksson, 1999), to get back into the labor market (Tan \& Tan, 2002), or to acquire a more core-organizational position (DiNatale, 2001). The motive that is based on reentering the labor market is sometimes also referred to as the "stepping-stone motive" (de Jong et al., in press). According to the stepping stone perspective alternative employment may not often be the preferred choice of individuals, but it is chosen nonetheless for instrumental reasons, as it may bring them a step closer to more permanent positions (Korpi \& Levin, 2001).

However, rather than being an either-or distinction, there is growing evidence that motives may be ambiguous. In other words, there may be a gray area since both types of motives may co-exist for individuals. Earlier research reports moderate correlations between voluntary and involuntary motives (Ellingson, Gruys, \& Sackett, 1998; Tan \& Tan, 2002). In a study on temporary workers, Krausz (2000) found differences between temporary workers depending on whether temporary work was a lifestyle, accepted only for the time being, or an entirely involuntary choice. A recent classification of temporary workers used three single motives chosen on theoretical grounds to reflect involuntary, voluntary, and stepping-stone motives and shows that these motives can co-exist (de Jong et al., in press).

The study of contract motives is only one of the ways to highlight the fact that individuals may differ in their reasons for taking on a certain contract arrangement. How employment and work conditions are experienced may not only be related to contract motives, but to other preferences and work values in a wider sense. An important factor that may more generally indicate what goals or aspirations an individual ties to their work or, in other words, what latent needs their work satisfies (Jahoda, 1982), is that of work involvement. Work involvement is defined as a "normative belief about the value of work in one's life” (Kanungo, 1982, p. 342), which is supposed to 
arise as a function of past cultural conditions and socialization. The work involvement of temporary or part-time workers has rarely been given specific attention. Some research has earlier suggested that those in alternative employment may be more involved in other life roles, and, thus, work may be less central to them (Martin \& Sinclair, 2007; Thorsteinson, 2003). However, this may be called into question, given the large number of involuntaries in alternative employment forms as well as the differences in the backgrounds of temporaries and part-time workers. Also, with the growing number of highly educated individuals who have invested significant time and energy into the work-related parts of their lives, it may be doubtful whether work involvement can generally be assumed to be low. Instead, it is rather plausible to expect that work involvement would vary in a way similar to that of permanent workers. Indeed, research on work involvement has found that older workers generally report higher work commitment (Gallie, White, Cheng, \& Tomlinson, 1998; Isaksson, 1990), and that work involvement is stronger among individuals with higher education (Gallie et al., 1998). Gender differences may also play a role in regard to work involvement, particularly in those families who hold to traditional values in which the woman is in charge of the housework and the man is the breadwinner (Artazcoz et al., 2004). Given all of this, it is conceivable that, for example, older male temporary workers may have a higher work involvement than female temporary workers of the same age, and that work may be less important for temporarily working high-school students than for temporary workers who have completed educations and have high career aspirations. In sum, the associations between contract motives, work involvement, and individual characteristics (see e.g., DiNatale, 2001; Gallie et al., 1998; Wiens-Tuers \& Hill, 2002), and also work-related variables (de Jong et al., in press) have been focused upon in several research studies. In contrast, the question of how motives and work involvement explain workers' reactions to alternative employment has yet to be properly explored in the literature.

With respect to outcomes, earlier research has mainly found that voluntary motives are related more to job and pay satisfaction, while their relation to performance has been found to be weak (Ellingson et al., 1998; Tan \& Tan, 2002). However, these may not be the only connections, as different motives may relate to different stress and strain levels and thus associate with wellbeing and health. For example, it has been suggested that choosing temporary employment entirely on voluntary grounds may give rise to a feeling of being in control over one's life and career (Krausz, 2000), which should positively relate to health and well-being. Drawing on the stress theory suggested by Lazarus and Folkman (1984), it is also conceivable that the degree of voluntary, mixed, or involuntary choice one has influences the appraisal of alternative employment conditions. For individuals with 
involuntary motives, alternative work arrangements that often imply frequent job changes or unreliable earnings may be perceived as stressful, whereas those with entirely voluntary motives may not consider these characteristics to be a problem. Thus far, only two studies have analyzed the associations of motives, stressors, and well-being, and found support for the suggested associations with well-being (Krausz, 2000, Silla, Gracia, \& Peiró, 2005). However, since both of these studies simply categorized workers into either a voluntary or an involuntary group, it is still unknown what effect having a combination of ambiguous motives may have on well-being.

Concerning work involvement, most of the available evidence regards the unemployed, and indicates that a high degree of work involvement may make it difficult to adapt to unemployment (e.g., Warr \& Jackson, 1985), which seems to have a negative impact on well-being (see also Isaksson, Johansson, Bellaagh, \& Sjöberg, 2004). Considering these findings, involuntary temporary or part-time workers with high work involvement may perhaps have difficulties coping with the threat of unemployment that is inherent in time-limited contracts, or they may dislike the shortening of their hours. Consequently, their reactions in terms of well-being or organizational attitudes may be unfavorable. On the other hand, as work involvement is known to influence attitudes and health positively, it might serve as a buffer against the negative consequences of perceived job insecurity (Sverke, Hellgren, \& Näswall, 2002). Looking at it from another angle, if low work involvement is presumed to be an indication that work does not have an important function for an individual, it could also be speculated that the potential effects of any unfavorable employment conditions would be reduced.

Since studies on how formal contract types relate to both different contract motives and work involvement regarding alternative employment forms are rare, it largely remains unclear how the interrelation of motives and work involvement in temporary and part-time workers relates to well-being and distress. Nevertheless, it appears conceivable that the existing heterogeneity of individuals' contract motives and work involvement may comprise yet another factor which, if more thoroughly investigated, could help explain individuals' reactions towards alternative employment.

\section{Differences in job and contract preferences}

Whereas the contract motives that are measured in regard to temporary work can only be applied to this type of work, the assessment of general contract preferences can be applied to both temporary and permanent work. The information of both measurements is thought to be related, since many 
researchers presume that the fit of current contract to preferences is based on the individuals' patterns of contract motives. However, instead of specifying the contract motives for temporary work, it can be more advantageous to ask whether the contract generally fits the employees' own preferences, since this allows permanent workers' preferences to be assessed and controlled for (De Cuyper \& De Witte, 2007). This seems to be important, since research has found that not all permanent contract holders - as was simply assumed in earlier research (e.g. Krausz, 2000; Krausz, Brandwein, \& Fox, 1995) prefer their arrangement (Aronsson \& Göransson, 1999).

In the previous section, it was argued that preferences may not only relate to contract motives but also to work involvement. In this section, yet another way to broaden the perspective of preferences is discussed. Since different contractual arrangements are found in a broad variety of different jobs today, it is plausible that studying the role of preferences may also benefit from disentangling to what extent the individuals' preferences for work evolves from the contract, but also the job that is offered. Surprisingly little scientific attention has been directed to this differentiation of preferences for job and contract in alternative employment (for an exception, see Aronsson, Dallner, \& Gustafsson, 2000; Aronsson \& Göransson, 1999), and therefore, the empirical evidence on the concept of 'job preference' and its associations with outcomes, as well as its relations to contract preferences, is rather limited.

Like contract preferences, job preferences are also believed to be shaped by a variety of motives, albeit not the same ones. The fit of educational background and work experiences to the job requirements, and the fit of interests and competences to the job tasks, or even career aspirations and career motives are all important in influencing an individual's job preferences. In fact, the growing number of highly educated trained workers in the alternative workforce, the so-called knowledge workers (Guest, 2004), probably base their assignment preferences not only on contract conditions but also on job preferences. On the other hand, reports also show that the available number of jobs demanding high skills falls short of the growing number of highly skilled workers in most industrialized countries (Rifkin, 1995). Also, those who lack work experience or have been in positions with limited opportunities for training and development may have difficulties acquiring a job that suits their interests and preferences. As a consequence, a significant proportion of workers, particularly in the alternative workforce, seem to be offered jobs with low intrinsic quality (Corral \& Isusi, 2004; Loughlin \& Barling, 2001) which may not match their desire for stimulating work and career opportunities. 
It is very likely that working in a preferred job would have a positive impact on one's well-being and attitudes towards the organization. To work in a preferred job, which suits one's career aspirations or chosen occupational education, may provide the necessary congruence between one's personal goals and interests, which is known to be a source of well-being (Diener et al., 1999; Ryff, 1989). It has also been pointed out that having a preferred job may grant individuals a greater sense of being in control over their working lives and career development, and this feeling of mastery may also serve as a source of well-being (Warr, 1987). Furthermore, working in one's preferred job may be perceived as more meaningful, which should be beneficial for the organization since it may foster better employee identification and commitment. Those who are forced to accept a nonpreferred job, on the other hand, may appraise the job and the organization that provides this job more negatively, which may associate with impaired well-being and make withdrawal more likely. Indeed, not being in a preferred job may be related to psychosomatic complaints (Aronsson \& Göransson, 1999), and is believed to lead to negative feelings towards the job as well as reduced motivation (Loughlin \& Barling, 2001).

Another interesting question in this context is how job preferences interrelate with contract preferences and with different contract types. The evidence thus far shows that those permanent employees who are not in their preferred job (Aronsson \& Göransson, 1999) or, otherwise, not in their preferred contract (De Cuyper \& De Witte, 2007; Guest et al., 2006) tend to report more negative well-being or negative organizational attitudes than temporary workers in the same situation, that is, in non-preferred jobs or contracts. These studies, however, only distinguished between permanent and temporary workers and only looked at either job preferences or contract preferences. The relative importance of job preferences in comparison to contract preferences remains unclear, and the question of whether job and contract preferences have a combined multiplicative or additive effect is still unanswered. Additionally, the associations between these preferences and contract types need to be better understood, which is why a more specific differentiation of employment contracts, beyond the permanent-temporary dichotomy, appears to be an important extension to earlier studies.

\section{Differences in perceived job conditions}

The differences among the employees of the alternative workforce also concern the job conditions under which they work, since the length and stability of the job, its inherent tasks and duties, the degree of responsibility demanded, and the opportunities for using skills and knowledge seem to vary widely. 
Consequently, individuals' perceptions of their job conditions may vary for at least three reasons. Firstly, alternative employment contracts may indeed imply poor work conditions, as has long been hypothesized (see, e.g., Beard \& Edwards, 1995). Secondly, however, different alternative employment forms may provide different job conditions; e.g., it is conceivable that being employed on-call would allow fewer opportunities for taking on tasks requiring responsibility than being employed as a substitute for a core worker would, as such a job would entail taking over the person's regular responsibilities. Thirdly, perceptions of job conditions may differ due to individual background differences relating to educational level or occupational achievement, as such differences may contribute to the formation of different expectations and notions about what constitutes a stimulating job or good work in general. In sum, the perceived job conditions of workers in alternative employment contracts can differ from permanent workers, among each other, and even among those within one and the same employment form and job, given that individuals who fill these jobs differ.

The associations between employment status and job conditions have been the subject of several research studies. European surveys found in 1995 as well as in 2000 that work in alternative employment implied lower autonomy and engaging in repetitive and less skill-demanding tasks, which are qualities that are similar to those of 'passive jobs' (Goudswaard \& Andries, 2002). Similarly, part-time workers often report greater monotony, lower levels of task complexity, and an under-use of skills when compared to permanent full-time workers (Corral \& Isusi, 2004). Some authors have concluded that work in alternative employment, particularly in temporary contracts, is similar to that of 'high strain' jobs, characterized by perceptions of low control in combination with higher levels of work intensity and a greater pace (Paoli \& Merllié, 2001). However, again, differentiations have to be made (Aronsson et al., 2002; Wikman et al., 1998). Among temporary workers, a Swedish study has found that those in project work reported the highest levels of influence and control over their work, whereas on-call workers perceived the lowest levels of control. Young age as well as low education seemed to lessen the degree of control (Aronsson et al., 2002).

A number of well-established stress-models, among which the Job DemandControl model (Karasek \& Theorell, 1990) may be the most well-known, have been used in demonstrating that perceptions of the job and, in this case in particular, the aspects of control and demand, associate with physical health and psychological correlates of subjective well-being (de Jonge et al., 2001; Morrison, Payne, \& Wall, 2003). However, the bulk of the research using the Job Demand-Control model has related to permanent employees. 
Whether or not the various perceptions of job conditions have the same implications across all types of employment forms may, however, be questioned. For example, for those who only work some days or hours a week, high job demands may end up being less problematic, since there is enough time for recovery in between working occasions. Likewise, higher demands may be welcomed by employees who would prefer a more permanent or full-time employment and, thus, want to demonstrate their competences and willingness to work. Another hypothesis, which has been put forth in a recent Belgian study, is that perceived job characteristics may not have the same relevance for the well-being and work-related attitudes of temporary workers as compared to permanent workers (De Cuyper \& De Witte, 2006). The results in this study indicated that workload did not have the same detrimental effect for temporary workers as it did for permanent workers. Likewise, autonomy did not have as much of a positive effect for temporary workers as it did for permanent employees. Further empirical investigations seem to be necessary to better understand the combined effects of contractual agreement and perceived job conditions. In addition, more insight may be able to be gained in regard to workers' reactions with the use of a more specific differentiation of employment status.

Apart from these classical job characteristics, it is believed that the work conditions in alternative employment also have to be understood in relation to the distribution of risks and control in a broader sense (Aronsson et al., 2002), and, in this regard, perceptions of job insecurity have often been singled out (see, e.g., Goudswaard \& Andries, 2002; Isaksson, Aronsson, Bellagh \& Göransson, 2001). The psychological concept of job insecurity refers to an individual's concerns about the continuance of his or her job (Hartley, Jacobson, Klandermans, \& van Vuuren, 1991). Two recent metaanalytic studies have identified perceptions of job insecurity as a risk factor associated with impaired physical and mental health (Cheng \& Chan, 2008; Sverke et al., 2002). Although many previous studies have established that there are high correlations between perceptions of job insecurity and temporary employment (De Cuyper et al., 2005; Sverke et al., 2004), the perception of job insecurity may not be shared by all workers in alternative employment contracts. Part-time workers have been found to report lower job insecurity than permanent full-time workers in a Swedish study among health care workers (Sverke et al., 2000). In a European survey, one out of four temporary workers had reported that their employment was secure (Letourneux, 1998), which is plausible if these workers had been promised contract renewal or eventual movement into a permanent contract. It should also be kept in mind that since perceptions of job insecurity are subjective, those who have chosen a temporary contract may simply not consider it insecure. 
Similar to much of the research on job characteristics, investigations on the consequences of perceived job insecurity have mainly focused on the permanent workforce. However, when permanency, and thus relative employment stability, is not part of the contract, it may be questioned whether perceptions of having an insecure job would still have the same detrimental effect on attitudes or well-being (P. Virtanen et al., 2002). There is growing evidence that the associations between outcomes and job insecurity may depend on the contractual agreement, since several studies have reported that attitudes and well-being are negatively affected when permanent workers feel job insecurity, while this effect was not found in temporary workers (De Witte \& Näswall, 2003; Mauno, Kinnunen, Mäkikangas, \& Nätti, 2005; P. Virtanen et al., 2002). A frequent interpretation of this finding relates to the psychological contract, which is determined by the perceptions both parties (employee and employer) have in regard to the terms of their exchange agreement (Conway \& Briner, 2002). For permanent workers, it is assumed that the psychological contract is violated when they feel job insecurity, whereas temporaries expect feelings of job insecurity to be part of their arrangement. However, once again, all these studies have simply dichotomized contracts into either permanent or temporary. Because of this, it can be argued that formal contract conditions need to be better separated in order to investigate whether these results would be obtained for the entire alternative workforce, which would help to further validate the violation hypothesis related to the psychological contract. 


\section{Method}

\section{Samples}

The studies in this thesis are based on two different data collections, which differ in terms of time of data collection, sectors, and selection process.

For Study I and IV, data was collected in a research project designed to analyze the process and consequences of reorganization in acute care hospitals in the Stockholm area of Sweden (Öhrming \& Sverke, 2001; Sverke, Hellgren, \& Öhrming, 1999). The data used in this thesis was collected in 1998 through the use of a questionnaire that was sent to the homes of the entire staff of two hospitals undergoing organizational restructuring. Altogether, 2,455 employees received a questionnaire mailed to their homes, accompanied by a letter explaining the purpose of the study and reassuring that participation was voluntary and that the answers would be treated confidentially. After sending up to three reminders, a total of 1,505 filled-in questionnaires were returned in the prepared envelopes. Overall, this corresponds to a response rate of $61 \%$. The majority of the health care workers in this data were permanently employed on a full-time or part-time basis. About $13 \%$ were contracted on a temporary basis, under fixed-term or on-call contracts.

The data used in Study II and III were collected during 2004 in Sweden as part of a European research project known as PSYCONES (PSYchological

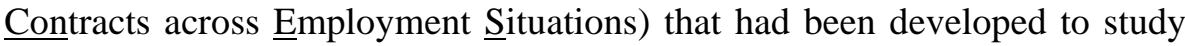
employment and psychological contracts across different employment situations through the examination of different contracts, sectors, and countries (Guest, Isaksson, \& De Witte, in press). Across all participating countries, data were collected in three different sectors (retail, education, and food industry) containing reasonably large amounts of contract diversity. In each sector, at least seven different, large and small, private as well as public, organizations with reasonable shares of temporary workers were approached. In those companies willing to participate, questionnaires were distributed to at least five employees employed under permanent and temporary contracts, respectively. Altogether, this strategy resulted in a non- 
randomized sample in which, compared to the general population, alternative work arrangements are overrepresented. The Swedish data was collected from a total of 28 organizations, including 7 private companies in the food industry, 9 public and private schools for children as well as adults, a university department in the educational sector, and 12 various food markets, clothes stores, and building material suppliers in the Stockholm area. With the exception of one evening school that chose to mail the questionnaires to the homes of their employees, questionnaires were distributed at the work place. The completed questionnaires were returned to the research group in sealed envelopes or the sealed envelopes were collected by a coordinator in the organization who forwarded them to the research group after the prespecified deadline. After sending up to three reminders, a total of 768 participants returned their questionnaires, giving an overall response rate of $50 \%$.

\section{Measures}

The variables for capturing heterogeneity in employment contracts, individual differences regarding background and perceptions, and implications regarding attitudes and well-being indicators were measured by scales or as single items in both questionnaires. Table 1 provides an overview of all of the measures in terms of their origin and reliability, and shows in which studies they appear. For dichotomous variables, only the alternative scoring ' 1 ' is presented; ' 0 ', if not stated otherwise, corresponds to the logical alternative.

Table 1. Overview of used variables

\begin{tabular}{|c|c|c|c|}
\hline Variable & Study ${ }^{a}$ & Measures & $\begin{array}{c}\text { Reliability } \\
\text { (alpha) }^{\mathrm{b}}\end{array}$ \\
\hline \multicolumn{4}{|c|}{ Employment contract } \\
\hline \multirow[t]{2}{*}{ Formal contract } & I; II & $\begin{array}{l}\text { Temporary employment: } \\
1 \text { = fixed-term contract, } \\
0=\text { on-call contract }\end{array}$ & - \\
\hline & III & $\begin{array}{l}\text { Dummy coding resulting } \\
\text { in three variables: } \\
1=\text { Permanent part-time } \\
\text { contract ( }<24 \text { hours/week) } \\
1=\text { Fixed-term contract } \\
1=\text { On-call contracts }\end{array}$ & - \\
\hline
\end{tabular}




\section{Individual background}

IV

Dummy coding resulting

in three variables:

$1=$ Permanent part-time

$1=$ Fixed-term contract

$1=$ On-call contracts

Age

Gender

Marital status

Child responsibility

Education

Vocation: Nurse

Vocation: Physician

Daytime

Working hours

Organizational tenure $\quad \mathrm{I} ; \mathrm{IV}$

Work status

Sector: Education

Sector: Food industry

Sector: Retail

\section{I; II-IV Years}

I; II-IV $\quad 1$ = Female

I; II; IV

$1=$ Cohabiting

$1=$ Children younger than

12 living in the household

\section{II, III \\ $1=$ Academic}

I; IV

$1=$ Nurse

$1=$ Physician

1 = Only daytime work

Average working

hours/week

Years worked in the

organization

$1=$ White collar worker

II $\quad 1$ = Education

II, III $\quad 1$ = Food industry

III $\quad 1=$ Retail

\section{Contract motives and work involvement}

Voluntary contract II

motives

Involuntary contract II

motives

Work involvement

II
Perceptions of job conditions

Job insecurity

IV

Job control

Role overload /Job

demands ${ }^{c}$

Role ambiguity

Role conflict

IV

I, IV

I

I
Adapted from Tan \& Tan (2002)

Adapted from Tan \& Tan $\quad .60$ (2002)

Kanungo (1982)

Ashford, Lee, \& Bobko $\quad .76$ (1989)

Sverke \& Sjöberg (1994) $\quad .81$ Beehr, Walsh, \& Taber $\quad .70 ; .81$ (1976)

Caplan (1971); Rizzo, .69 House, \& Lirtzman (1970) Rizzo et al. (1970)
71 60 6 81 .79 
Table 1. (cont'd)

\begin{tabular}{|c|c|c|c|}
\hline \multicolumn{4}{|c|}{ Preferences for job and contract } \\
\hline Job preferences & III & $\begin{array}{l}\text { Single item adapted from } \\
\text { Aronsson \& Göransson } \\
\text { (1999) }\end{array}$ & - \\
\hline Contract preferences & III & Clinton et al. (2005) & .90 \\
\hline \multicolumn{4}{|l|}{ Well-being } \\
\hline General health & II; III & $\begin{array}{l}\text { SF36 (Sullivan, Karlsson, } \\
\text { \& Ware, 1995; Ware, } \\
\text { 1999) }\end{array}$ & $.76 ; .72$ \\
\hline Mental distress & I; IV & GHQ12 (Goldberg, 1979) & $.82 ; .86$ \\
\hline Somatic complaints & I & $\begin{array}{l}\text { Isaksson \& Johansson } \\
\text { (1997) }\end{array}$ & .82 \\
\hline Life satisfaction & II; III & Guest \& Conway (1998) & $.78 ; .86$ \\
\hline Work-related irritation & II & $\begin{array}{l}\text { Mohr, Mueller, Rigotti, } \\
\text { Aycan, \& Tschan (2006) }\end{array}$ & .86 \\
\hline Work-related anxiety & II & Warr (1990) & .85 \\
\hline $\begin{array}{l}\text { Work-related } \\
\text { depression }\end{array}$ & II & Warr (1990) & .86 \\
\hline $\begin{array}{l}\text { Positive work-home } \\
\text { interference }\end{array}$ & II & Wagena \& Geurts (2000) & .82 \\
\hline Job-induced tension & I, IV & House \& Rizzo (1972) & $.84 ; .84$ \\
\hline \multicolumn{4}{|l|}{ Work-related Attitudes } \\
\hline Job satisfaction & I & $\begin{array}{l}\text { Hellgren, Sjöberg, \& } \\
\text { Sverke (1997) }\end{array}$ & .85 \\
\hline Organizational & III & Cook \& Wall (1980) & .68 \\
\hline commitment & I & Allen \& Meyer (1990) & .68 \\
\hline Turnover intentions & III & Adapted from Price (1997) & .84 \\
\hline & I & Sjöberg \& Sverke (2000) & .79 \\
\hline
\end{tabular}

${ }^{\mathrm{a}}$ Italic numbers of studies indicate that the variable was treated as a control variable

${ }^{\mathrm{b}}$ Where scale reliability cannot be estimated, this is indicated with '-،

c In Study I, this variable was labeled 'Role overload', whereas in Study IV, it was referred to as 'Job demands'

\section{Data analysis}

For the data analysis in this thesis, two different approaches were used, one focusing on individuals' patterns of variables and the other on single variables. Thus, the aspects of formal contract heterogeneity, individuals' diversity, and perceptions have been approached in two different ways, which is explained in more detail below. 


\section{Pattern versus variable approach}

A variable-oriented approach, as the name suggests, utilizes methods in which the main conceptual and analytic unit is the variable. This has been the predominant approach of the last decades, and due to the development of modern and powerful analytic tools and statistical packages, its analyses are becoming all the more sophisticated (Bergman, Eklund, \& Magnusson, 1991). In this approach, variables may be examined in a number of ways, for example, by identifying their mean differences or by analyzing the linear associations between them. This is often accompanied by a modeling of the found relationships between the variables, which is guided by pre-specified hypotheses.

The analysis of patterns can be considered an alternative approach that has become more influential in recent years, mainly due to its conceptual and analytical development (Bergman, Magnusson, \& El-Khouri, 2003). In this approach an emphasis is put on the profile or gestalt, which has led to it also being referred to as a holistic or person-oriented approach (Magnusson, 1998). In this regard, just studying single variables and their linear associations with outcomes would therefore not provide sufficient information about an individual. Researchers using this approach attempt to redirect the focus of psychological analysis by regarding the individual as the basis of their inquiry. In other words, not single variables, but individuals with their specific combinations of variables constitute the entity of study (Baltes \& Nesselroade, 1979), and this allows the pattern approach to encompass and set forth the functioning totality that is formed by the interacting elements involved (Bergman \& Magnusson, 1997). Instead of analyzing how one variable relates to the other, in this approach, individuals are grouped according to similar patterns of variables, and the analyses concentrate on finding out whether these patterns that differentiate the groups may relate to and thus explain the differences in the outcomes studied.

This thesis does not attempt to advance one approach over other, but rather has aspired to incorporate them both by making use of their different strengths, without denying that they also may have weaknesses. For while a variable approach can provide the "guiding power of a sound model" (Bergman et al., 1991, p. 19), a pattern approach gives a better opportunity for covering aspects of reality that are not easily accessible with the other approach. Indeed, some aspects of reality may be rather difficult to model in a variable approach, such as those involving interactions that include more than three variables. Another difference is that in a variable approach, each single variable's contribution to the explained variance in a hypothesized outcome may be tested, whereas in a pattern approach, it is impossible to 
track down each single variable's contribution to the outcome. However, this latter, potential limitation is not of relevance in this investigation, since the concern here is more with the pattern approach's ability to show how much the meaning of the variables change when they all interact. By looking at what the pattern of a set of variables means for the outcomes, this approach attempts to account for the complexity in an individual's reality.

The point to be made is that both approaches deliver different information. Regarding these studies, more specifically, the variable approach has been used to calculate how much, e.g., type of contract, job characteristics, and individual variables explain variance in well-being and organizational attitudes. The pattern approach, on the other hand, has been used to group individuals according to a set of these variables, whereby they were split into subgroups with similar profiles, and then compared in regard to their wellbeing measures or organizational attitudes. In so doing, an examination could be made into how entire profiles may explain a reaction. More exact information on the statistical tests used is described below.

\section{Cluster analysis and analysis of variance}

In Study I and II, the pattern approach has been applied to capture heterogeneity in alternative employment forms, and here, specifically in regard to temporary workers. In both studies, the heterogeneous group of temporary workers was split into smaller and more homogeneous subgroups, consisting of those individuals who displayed similarities in regard to the variables under consideration. For this purpose, conventional cluster algorithms are typically used to analyze the inherent structure in the data and to find mutually exclusive groups, so that all cases (individuals) grouped together have as similar as possible patterns, and the others have patterns as dissimilar as possible (Bergman et al., 2003). A range of different methods for this classification process are available; however, agglomerative hierarchical cluster analysis is the one most commonly used. In this method, each case is initially treated as one cluster. In the iterative merging process, two similar cases can be put together, or new ones can be added into a cluster until all cases are eventually merged into one cluster. Various methods for estimating the similarity of cases are available, although the WARD-method is one of the best performing ones in terms of the size, homogeneity, and interpretability of the resulting clusters (Bergman et al., 2003). The WARD-method uses the overall sum of the squared, withincluster Euclidian distances to estimate how much the error sum of the squares (ESS) increases when cases that are similar but not identical are merged in a cluster. In order to keep error variances as minimal as possible, the pair of clusters that results in the least increase of ESS is chosen for fusion in each step until all of the cases are finally clustered. In other words, 
the analysis itself provides no stop criteria for the optimal partitioning of the data into dissimilar groups.

To determine the best solution of clusters, the analyst has to decide at what criteria the further fusion of clusters should stop. Whereas Study I and II both used hierarchical clustering algorithms according to the WARDmethod, different stopping criteria were applied in each study. In Study I, which used the statistical package for clustering in SPSS, the last iterations were all printed out in order to help determine at which point two theoretically distinct clusters merged. Also, all cluster solutions were inspected foremost in terms of their interpretability. As an additional safeguard, the most meaningful theoretical solution was tested to check whether it resulted in significant mean differences in regard to the clustering variables. In more recent years, more sophisticated methods of validation have been suggested, such as the inspection of (1) the occurrence of sudden drops in the explained error sum of squares (ESS), which would indicate that too few clusters have been reached, (2) the explained ESS, which should exceed at least $50 \%$ of the total ESS, and (3) the homogeneity coefficients for each cluster, which should preferably be under 1.00 (for a discussion, see Bergman et al., 2003). Accordingly, these stopping rules were used in the estimations performed by the statistical package SLEIPNER 2.1 (Bergman et al., 2003) to determine the most suitable cluster solution in Study II.

To analyze whether the identified clusters also differed in regard to outcomes, multivariate analyses of variance (MANOVA) procedures were used. In Study I, three MANOVAs were conducted, one for each set of dependent variables, namely attitudes, role stress, and health indicators. Post-hoc Bonferroni tests were employed to analyze the between-group differences in cases where the univariate effects were found significant. In Study II, multivariate variance analyses with covariates (MANCOVAs) were conducted, where individual demographics were kept constant while the work-related and general well-being of the groups were compared. Since the measures of both types of well-being correlated significantly, Roy-Bargman stepdown F-tests were used to account for the related dependent variables. In performing this technique, a variable that had been tested for group differences in the univariate analysis was added to the set of covariates, which allowed them to be related to the next dependent variable in the test.

\section{Regression techniques}

To complement the pattern approach, the associations between the sets of variables have also been analyzed, in Study III and IV, for the purposes of learning more about how the variables that may contribute to the heterogeneity in alternative employment may explain various outcomes. In 
both studies, hierarchical regression analyses were employed, and in each of them, demographic background characteristics have been controlled for by entering them first into the model. Thereafter, while holding individual differences constant, contract types were entered in order to find out how much of the variance in the outcome variables they could explain. The four contract categories were analyzed as a set of three dummy variables, with the permanent full-time contract group as the comparison group. In Study III, job and contract preference were added in the next step in order to estimate how much variance these variables explained in the outcomes, while holding type of employment contract and individual background characteristics constant. Finally, two- and three-way interactions were tested, that is, the effects of contract type $\mathrm{x}$ job preferences, contract type $\mathrm{x}$ contract preferences, or contract type $\mathrm{x}$ job $\mathrm{x}$ contract preferences were analyzed, and all interaction terms were simultaneously added in the last step of the model. Following recommended procedures (Aiken \& West, 1991; Cohen, Cohen, West, \& Aiken, 2003), continuous predictors were centered before calculating the cross-products in order to avoid artificial multi-collinearity. In Study IV, perceptions of job conditions were added after contract types and individual differences, in order to analyze how much these factors added to the variance explained in the outcomes. In the following steps, two-way interaction terms between contract type and each of the job conditions were added in order to analyze whether this added to the prediction of the outcomes. Following the procedures described for Study III, the interaction terms were created as cross-products between the contract type and job conditions, after centering the continuous variables.

\section{Overview: The studies in this thesis}

In Table 2, a general description of the four studies comprised in this thesis can be found. This table presents the central variables that are of focal interest in each study in terms of formal contract, individual differences and outcomes. Furthermore, information about the data material, with respect to data collection, year, included sectors, organizations and contracts, as well as the size of the effective sample with complete data, is summarized for each study. Finally, the overview also provides information on the analytic techniques used. 
Table 2. General description of the studies in this thesis

\begin{tabular}{|c|c|c|c|c|}
\hline & Study I & Study II & Study III & Study IV \\
\hline Formal Contract & Temporary employment & Temporary employment & $\begin{array}{l}\text { Permanent and temporary } \\
\text { employment }\end{array}$ & $\begin{array}{l}\text { Permanent and temporary } \\
\text { employment }\end{array}$ \\
\hline $\begin{array}{l}\text { Individual } \\
\text { Differences }\end{array}$ & $\begin{array}{l}\text { Individual background } \\
\text { characteristics }\end{array}$ & $\begin{array}{l}\text { Contract motives and } \\
\text { Work involvement }\end{array}$ & $\begin{array}{l}\text { Preferences for job and } \\
\text { contract }\end{array}$ & Perceived job conditions \\
\hline Outcomes & $\begin{array}{l}\text { Role stress, } \\
\text { Organizational attitudes } \\
\text { Well-being }\end{array}$ & Well-being & $\begin{array}{l}\text { Organizational attitudes } \\
\text { Well-being }\end{array}$ & Well-being \\
\hline Data material & $\begin{array}{l}\text { Data from the total staff } \\
\text { of two Swedish acute care } \\
\text { hospitals }\end{array}$ & $\begin{array}{l}\text { Swedish data from the } \\
\text { PSYCONES project }\end{array}$ & $\begin{array}{l}\text { Swedish data from the } \\
\text { PSYCONES project }\end{array}$ & $\begin{array}{l}\text { Data from the total staff } \\
\text { of two Swedish acute care } \\
\text { hospitals }\end{array}$ \\
\hline Year & 1998 & 2004 & 2004 & 1998 \\
\hline Sectors & Health care sector & $\begin{array}{l}\text { Food industry, Retail and } \\
\text { Education }\end{array}$ & $\begin{array}{l}\text { Food industry, Retail and } \\
\text { Education }\end{array}$ & Health care sector \\
\hline Organizations & 2 organizations & 28 organizations & 28 organizations & 2 organizations \\
\hline $\begin{array}{l}\text { Types of } \\
\text { employment } \\
\text { contracts }\end{array}$ & $\begin{array}{l}\text { Fixed-term contract } \\
\text { On-call contract }\end{array}$ & $\begin{array}{l}\text { Fixed-term contract } \\
\text { On-call contract }\end{array}$ & $\begin{array}{l}\text { Perm. full-time contract } \\
\text { Perm. part-time contract } \\
\text { Fixed-term contract } \\
\text { On-call contract }\end{array}$ & $\begin{array}{l}\text { Perm. full-time contract } \\
\text { Perm. part-time contract } \\
\text { Fixed-term contract } \\
\text { On-call contract }\end{array}$ \\
\hline Effective sample & $\begin{array}{l}\text { Temporary employees }(N \\
=196)\end{array}$ & $\begin{array}{l}\text { Temporary employees }(N \\
=184)\end{array}$ & All employees $(N=716)$ & All employees $(N=954)$ \\
\hline Analytic method & $\begin{array}{l}\text { Agglomerative } \\
\text { hierarchical cluster } \\
\text { analysis in SPSS, } \\
\text { MANOVAs }\end{array}$ & $\begin{array}{l}\text { Agglomerative } \\
\text { hierarchical cluster } \\
\text { analysis in SLEIPNER, } \\
\text { MANCOVAs }\end{array}$ & $\begin{array}{l}\text { Hierarchical regression } \\
\text { analyses in SPSS }\end{array}$ & $\begin{array}{l}\text { Hierarchical regression } \\
\text { analyses in SPSS }\end{array}$ \\
\hline
\end{tabular}




\section{Summary of studies}

\section{Study I}

Work attitudes, role stress and health indicators among different types of contingent workers in the Swedish health care sector

It has been recognized that a more detailed distinction of alternative employment contracts is needed and that contingent workers differ in regard to the individual and contextual background factors that might influence their reactions towards this employment form (Aronsson et al., 2002). Furthermore, many of these background factors may only begin to matter when they appear together or interact with each other (Bergman \& Magnusson, 1997). Two individuals, for instance, may react differently to contingent work, with the only relevant background difference between them being that one of them is the sole breadwinner and the other is an additional income provider. In other words, an effect does not need to result from an accumulation of single variables, but may, rather, arise from the whole pattern of individual characteristics. Against this background, the objective of Study I was to find out whether factors concerning personal characteristics and work-related characteristics, as well as type of formal employment contract, together formed identifiable patterns that also differed in relation to work attitudes, stress, and health indicators.

The data for Study I came from data collections taken from two Swedish acute care hospitals. The sample was limited to contingent workers $(\mathrm{N}=$ 196) with complete data sets for the analysis. Of these, a majority (58\%) worked on temporary fixed-term contracts, while the others (42\%) were employed as temporaries with on-call arrangements. Agglomerative hierarchical cluster analysis in SPSS, using the WARD-method was performed on a set of background variables representing personal characteristics (age, gender, child responsibility, cohabiting) and workrelated characteristics (profession, working time, organizational tenure), as well as type of formal employment contract. Five different patterns of background characteristics in the sample were found, but one pattern was omitted from further analysis, due to its limited size. The remaining four 
clusters were described as follows. The cluster of Younger nurses was mainly comprised of female nurses on fixed-term contracts who were younger and, most often, single. The second cluster, called Physicians, was gender-balanced ( $45 \%$ men), and consisted solely of physicians who were working irregular hours in a fixed-term contract. The third cluster, labeled Middle-aged nurses, consisted only of nurses. Individuals in this group had the highest average age and were, by a large majority, female. Moreover, only a minority of them had fixed-term contracts, and their average organizational tenure was longer than with any other cluster. Finally, a fourth group, the Support staff, was found, where a majority were employed in support activities as, e.g., secretaries, laboratory assistants, and physiotherapists. This group worked daytime only, their average age was comparable to that of Physicians, and like the Middle-aged nurses, a large majority of its members were women. Despite having many similarities in regard to work attitudes, role stress, and health, the patterns differed in respect to organizational commitment, role overload, and job-induced tension. More specifically, Middle-aged nurses reported significantly lower organizational commitment than the individuals of the Support staff cluster. Physicians perceived significantly higher role overload than Middle-aged nurses and Support staff. Furthermore, Physicians reported significantly more job-induced tension than Middle-aged nurses.

The differences found did not seem to connect to single factors, but to combinations of factors in the patterns. For example, Physicians showed higher role overload than Middle-aged nurses and Support staff, but not Younger nurses. Hence, to just attribute this to profession would be too simple. Here, rather, responsibilities together with experiences, which Younger nurses may not have acquired to the same degree as the other groups, may be part of the explanation. The weaker organizational ties of Middle-aged nurses may be related to a combination of their specific type of contract and tenure circumstances. As this group tended to work on-call and, also, had the longest organizational tenure, its members had had a greater exposure to organizational changes than those of the other clusters. However, Middle-aged nurses also showed lower job-induced tension than Physicians, but not the other groups. The specific combination of age and long tenure, accompanied with a rather limited contract, which implied a limited presence at the workplace, may, again, explain this finding for the group.

It can be concluded from Study I that there is heterogeneity in individuals' demographic and work-related backgrounds, which may be better understood if analyzed using a holistic pattern approach. Those differences that emerged in regard to work attitudes, role stress, and health were attributable to certain unique combinations of factors, or patterns, that 
applied to groups of contingent workers. In sum, more could be learned about the different reactions of the contingent workforce when contract heterogeneity was taken into account along with individual differences. Furthermore, with the pattern approach, the person rather than just single variables could be better accounted for.

\section{Study II}

Patterns of contract motives and work involvement in temporary work: Relationships to work-related and general well-being

Temporary workers are known to differ in regard to their reasons for taking on temporary contracts (Tan \& Tan, 2002), and this has been found to relate to attitudes and performance (e.g., Ellingson et al., 1998), while its potential associations with well-being have often been neglected in the studies. Temporary workers may also differ in respect to their work involvement: for some, work may only play a minor role in their lives, whereas, for others, it may be of central importance (Kanungo, 1982). Knowledge about the work involvement of temporary workers has been limited. However, drawing on unemployment research, it may be fruitful to investigate how work involvement interacts with different contract motives. For example, when contract choices are limited in regard to continuous employment, what impact might viewing one's work as a central aspect of life have on wellbeing? To address such questions, Study II sought to clarify whether patterns could be found for temporary workers, based on their contract motives and work involvement, before also exploring whether these patterns differed in regard to the indicators of work-related and general well-being.

In Study II, data collected within the European project, PSYCONES, was used. The final sample for the study was limited to temporary workers $(\mathrm{N}=$ 184) with complete data. About one out of every four temporary workers in this sample (24\%) were employed on-call, but the majority (76\%) had a fixed-term contract. Almost half of the individuals in this sample (46\%) were in the educational sector, one third were in the food industry (34\%), and only a minority (20\%) worked in retail. Agglomerative hierarchical cluster analysis, using the WARD-method in SLEIPNER, was performed on standardized values of the clustering variables of voluntary motives, involuntary motives, and work involvement. Six patterns, differing in their shape and/or magnitude in terms of both contract motives and work involvement, could be identified. One group, The Involuntaries, reported more involuntary than voluntary motives for taking on temporary contracts, and expressed a low level of work involvement. For the group labeled The Balanced, voluntary and involuntary motives were reported equally often, 
and work involvement was rather high. The pattern of another group, The Accepters, was characterized by the lowest involuntary contract motives of all groups, and its levels of work involvement and voluntary motives were below scale midpoint, as more of an acceptance than a deliberateness was expressed towards these factors. The Misplaced had signed the temporary contract largely due to involuntary motives, and reported very low levels of voluntary motives and work involvement. The Involved comprised a small group of 12 individuals who had the highest work involvement of all groups, as well as a motive pattern that expressed typically involuntary temporary work. The Indifferent showed a tendency for more involuntary than voluntary contract motives, but had levels around the scale midpoint that expressed no clear preference; they also exhibited the lowest work involvement of all groups. In sum, involuntary contract motives was a strong element in most patterns. In two groups, voluntary and involuntary motives occurred simultaneously (i.e., in the Balanced and to some degree in the Indifferent), but no truly voluntary group was found. Work involvement was rather low for most of the groups, and combined with motive patterns in different ways.

After controlling for background characteristics, these patterns were found to differ in regard to aspects of work-related and general well-being, specifically in terms of anxiety and depression, positive work-home interference, general health, and life satisfaction, but not work-related irritation. This finding was especially prevalent for groups at risk (the Indifferent and the Misplaced) as well as for groups with positive tendencies (the Balanced and the Involved). These results revealed that groups whose involuntary contract motives were counterbalanced with voluntary motives or work involvement had more favorable well-being outcomes. Furthermore, the results suggested that temporary work may be most problematic for those who are engaged in involuntary temporary work and also report low work involvement. Despite not wanting to get very involved in work, individuals in these groups may nevertheless feel compelled to put in an extra effort in order to increase their chances of receiving contract renewal or permanent employment.

Overall, in Study II a variety of patterns were found to emerge with regard to how temporary workers' voluntary and involuntary contract motives combine with their work involvement. With the pattern approach, the differences in a range of well-being indicators could be more easily arranged and thereby understood. Compared to the small or insignificant correlations between single pattern variables and outcomes that limit many evaluations, the advantages of the holistic person approach become evident. It could be concluded from the results that, apart from contract heterogeneity and individual background characteristics, there is also an individual diversity to 
be found in contract motives and work involvement. The examination of this heterogeneity, especially as an entity in terms of patterns, can help us enhance our understanding about the different reactions to temporary work particularly in regard to well-being.

\section{Study III}

Well-being and organizational attitudes in alternative employment: The role of contract and job preferences

Apart from the heterogeneity in employment status that may account for inconsistent findings in regard to well-being and organizational attitudes, such findings may be shaped by the fact that individuals differ in their job and contract preferences (Aronsson \& Göransson, 1999). Some employees accept alternative work arrangements because they are interested in the job, or because they prefer working in alternative employment contracts. Others are forced to accept any assignment they are offered in order to avoid unemployment (De Cuyper et al., 2005). The aim of Study III was to investigate the single and combined effects of different types of employment contracts (comparing permanent full-time contracts to permanent part-time contracts, fixed-term contracts, and on-call contracts) as well as the effects of individuals' job and contract preferences on their well-being (general health, life satisfaction) and organizational attitudes (organizational commitment, intentions to quit).

The data set for Study III came from the European project PSYCONES and had been collected from different organizations across three different sectors (food industry, retail, and education). After a listwise deletion of missing data, a sample size of 716 individuals was reached, which served as the input for the analyses. Of these individuals, a majority (65\%) were employed under permanent full-time contracts, one out of ten (10\%) were permanent part-time workers, almost one-fifth (19\%) worked as temporary employees in fixed-term contracts, and six percent were temporarily employed on-call. With respect to sector, 36\% worked in the educational sector, 35\% in the food industry, and $29 \%$ in retail. Hierarchical regression analyses were employed, and demographics were controlled for in the first step. The final model revealed that the different employment forms were either weakly or non-significantly associated with well-being. When it came to organizational attitudes, on-call workers reported significantly lower commitment than permanent full-time workers, and all three alternative employment forms displayed lower intentions to quit than permanent full-time workers. Job preferences associated positively with all four outcomes. Contract preferences displayed positive associations with life satisfaction and 
negative associations with intentions to quit, but were unrelated to general health and organizational commitment. The test of interactive effects revealed that job and contract preferences had a significant multiplicative association with life satisfaction, but not with the other outcomes. Contract preferences and type of contract did not interact. Job preferences had a positive effect on permanent full-time workers' commitment, whereas no such effect was found with on-call workers. Also, job preferences diminished intentions to quit among permanent full-time workers significantly more than among fixed-term employees. Three-way interactions were found for general health and intentions to quit. Concerning general health, it was found that high contract preferences together with low job preferences tended to buffer negative reactions regarding fixed-term but not permanent full-time work. With respect to intentions to quit, high contract preferences in combination with low job preferences were shown to relate to lower intentions to quit for those in permanent part-time work, whereas among permanent full-time workers, the level of job preferences alone related to intentions to quit, without interacting with contract preferences.

The results of Study III demonstrated that contract heterogeneity was unable to explain variations in well-being. Instead, the contract differences appeared to relate to organizational attitudes. Interestingly, all of the 'alternative' groups reported lower intentions to quit than the permanent full-time workers, despite the fact that they, with the exception of the on-call employees, expressed levels of commitment similar to that of the permanent workforce. This finding suggests that the established association between commitment and intention to quit may be worth questioning in the case of alternative workers, since quitting is apparently a less often considered option for these workers. In a relative comparison, Study III found that job preferences were more consistently and robustly related to the outcomes than contract preferences, which also provides support for the notion that the investigation of job preferences is indeed a valuable direction to consider when exploring the impact of choices across different employment groups (Aronsson \& Göransson, 1999). An inspection of the interaction terms, however, revealed that job and contract preferences may have different roles in different employment groups. This has also been suggested by earlier research (De Cuyper \& De Witte, 2007). Job preferences were found to be more predictive for the permanent full-timers than for the alternative workforce, particularly when attitudinal outcomes were considered. Contract preferences, however, interacted with job preferences among on-call and permanent part-time workers, insofar as those with high contract preferences and low preferences for the job showed less negative results in regard to general health and intentions to quit. Thus, individuals' contractual preferences were determined to play a role for those working under certain 
types of alternative contracts, since having a preferred contract seemed to buffer the negative outcomes of being in a non-preferred job.

\section{Study IV}

Comparing three alternative types of employment with permanent full-time work: How do employment contract and perceived job conditions relate to health complaints?

Several authors have argued that the role of employment status needs to be investigated beyond the simple permanent-temporary dichotomy in order to better understand its consequences for well-being and attitudes. To accomplish this, recent evidence has suggested not only that there is a need to better differentiate between contract types, but that perceptions of job conditions (job control, job demand, job insecurity) need to be taken into consideration, including those which are known to differ for workers in different employment contracts (Goudswaard \& Andries, 2001; Wikman et al., 1998), and those which are well-known correlates of well-being. Accordingly, Study IV was conducted to investigate the relative importance of contract type (comparing permanent full-time workers to permanent parttime workers, fixed-term employees, and on-call workers) and perceived job conditions for health complaints (job induced tension, mental distress). Furthermore, Study IV aimed at investigating whether contract types and perceptions of job conditions had any interactive effects.

The data used to investigate these issues were taken from the above study on the health care personnel in two Swedish acute care hospitals, Study I. The effective sample comprised 954 individuals after a listwise deletion of the missing data in variables used in the analysis. A majority of the individuals (59\%) were employed under permanent full-time contracts, about a third (29\%) worked under permanent part-time contracts, nine percent were employed as temporaries on a fixed-term basis, and four percent had temporary on-call contracts. After applying hierarchical regression analyses and controlling for demographic variables in the first step, the final model revealed that type of employment contract had only weak associations with mental distress and that it did not associate with job-induced tension. In contrast, perceptions of job conditions appeared to be robustly related to both indicators of health complaints. More specifically, higher levels of job control significantly diminished health complaints. High levels of perceived job demand and high job insecurity increased reported mental distress and job-induced tension. No interactive effects between employment status and either job control or job demand were found. In contrast, employment status interacted with perceived job insecurity. Fixed-term workers and permanent 
full-time workers reported more health complaints when experiencing high job insecurity. For on-call workers, however, perceived job insecurity was unrelated to mental distress and job induced tension. Furthermore, job induced tension, but not mental distress, was unrelated to permanent parttime workers' perceptions of job insecurity.

Apparently, a mere comparison of contracts, even with improved differentiation, may not reveal much about the possible similarities or differences in employees' well-being. Perceptions of job conditions, on the other hand, appeared to be important correlates of individual well-being, and in this sample, no indications of an interactive effect between employment status and either job demands or job control, respectively, were found. In other words, the results indicate that both job control and job demands associate with well-being in the expected direction across all employment groups. However, employment status altered the association between job insecurity and well-being in respect to on-call work and, to a lesser extent, permanent part-time employment, whereas no such result was found for fixed-term workers. This finding underlines the importance of differentiating between the alternative employment groups when studying their contractual agreements in light of individual perceptions. As this study demonstrates, when investigating the circumstances surrounding employee well-being, incorporating aspects of contract heterogeneity along with differences in individual perceptions can reveal more information than any of these factors would alone. 


\section{Discussion}

With the objective of generating more knowledge about alternative employment arrangements and their consequences for the individual, this thesis was guided by two important assumptions, namely that employment contracts and their outcomes need to be examined, firstly, not only in light of the heterogeneity in different contractual arrangements but, secondly, also in regard to the differences among the individuals working in these contracts. Four specific research questions were focused on, each highlighting one aspect of individual differences along with contract heterogeneity in order to study individual outcomes in terms of well-being and organizational attitudes. The first question aimed at exploring whether individuals with different background characteristics and various forms of employment empirically could be classified into different groups according to role stress, organizational attitudes, and health indicators. The second question concerned whether individuals in alternative employment, when empirically grouped on the basis of their contract motives and work involvement, differed with regard to aspects of well-being. In the third question, the heterogeneity of employment contracts and job and contract preferences were considered by investigating the extent to which these factors, singly or in interaction, could be related to attitudes and well-being. Finally, the fourth question addressed the role of heterogeneous employment contracts by examining how they, either alone or through their interplay with perceptions of job conditions, associate with individuals' reported well-being. In the following, all of the findings are summarized, before the most relevant conclusions, methodological issues, and implications of this research are discussed.

\section{Formal contract and background characteristics}

The results of Study I showed that groups of temporary workers could be appropriately identified on the basis of their individual background characteristics and formal contracts with the aid of cluster analysis. The headings that were chosen for the groups, namely, Younger nurses, Middleaged nurses, Physicians, and Support staff, call attention to the obvious differences regarding age and profession, but the groups also differed on all input variables except for child care responsibility. Although life trajectories 
have become more individualized in the contemporary working world (Heinz, 2003; Shanahan, 2000), it is plausible that some life events are connected with certain periods of a person's life, for example, childbearing or entering into employment. Thus, to find background patterns that differ according to age is not unexpected. Differences between the patterns in terms of professions and contracts seem to parallel earlier classification results which found that temporary workers differed on the basis of their educational and professional backgrounds and work experiences (Marler et al., 2002). Thus, as has been concluded from more heterogeneous samples (Härenstam et al., 2003), Study I also demonstrates that lifestyle, demographics, and characteristics of work seem to be interrelated.

The important question, however, is whether these differences in background characteristic and employment contract patterns are meaningful for the investigation of occupational health (Härenstam et al., 2003; Silla et al., 2005) and work-related attitudes, such as satisfaction (Marler et al., 2002). For the identified clusters of Study I, differences in reactions could be found for the factors of attitudes, role stress, and health indicators. When the characteristics of the group patterns are looked at in relation to these results, some interesting observations can be made. The group of temporary workers with long organizational tenure, long work experience, and who mainly worked under on-call contracts (Middle-aged nurses) was most detached from the organization, but, at the same time, they also reported lower workrelated tension and role stress. These findings are somewhat contradictive to the results of variable approaches, which have indicated that tenure relates positively to commitment (Kochan et al., 1994), and that on-call work occasions the highest levels of impaired health (Aronsson et al., 2002).

Study I thereby provides valuable knowledge about what impact these factors may have together, as part of the same context, which is one of the strengths of the pattern approaches (Bergman \& Magnusson, 1997). In addition, the results may help to reveal the mechanisms behind why reactions towards alternative employment may not always follow established organizational theories (Connelly \& Gallagher, 2004). For Middle-aged nurses, for instance, the fact that they work on-call, in direct contact with patients and colleagues rather than with management, and in different shifts, including weekends, may be more likely to foster other forms of commitment (such as towards the profession or working group, see Gallagher \& Sverke, 2005) than organizational commitment to the hospital. Furthermore, the results illustrate how different kinds of professional experience and job tasks in combination with different temporary contracts can relate to different reactions. For example, having longer work experience together with limited responsibility and reduced presence in the organization may account for why Middle-aged nurses showed lower levels of role stress 
and job-related tension as compared to the Physicians, who had fixed-term employment, longer working hours, and more responsibility for patient treatment.

In sum, it appears that studying the interplay between work-related and personal background factors together with contract differences can further our understanding of the finer mechanisms underlying employees' reactions. Furthermore, in this examination, the use of the pattern approach has allowed for a more effective account of the network of factors that altogether reveal "who works where in what conditions" (Härenstam et al., 2003, p. 83), which has, in turn, led to a greater understanding of how these circumstances of individuals relate to the found consequences. Operating within an interactionist framework may provide more complex insights (Marler et al., 2002) and better guidance for the identification of suitable interventions in risk groups (Härenstam et al., 2003).

However, Study I also found many similar reactions of temporary workers with different background patterns. This may mean that patterns of background characteristics together with formal contracts reveal important insights, but not enough information on how alternative employment forms may be experienced by different contract holders. Also, since this study was rather exploratory in nature, it is not reasonably possible to make generalizations based on the identified groups. The important point, however, is to recognize that there are different types of temporaries, and that their distinctions should be taken into account in order to better understand their reactions (for a similar conclusion, see Marler et al., 2002).

\section{Contract motives and work involvement}

Study II focused on more psychological variables of work involvement and contract motives in an attempt to find out whether temporary workers, when grouped according to these factors, would differ in their subjective wellbeing. The study is one of the first to investigate work involvement in temporary employment as a factor influencing individual outcomes (for studies of work involvement as an outcome, see e.g., Isaksson et al., 2001; Krausz et al., 1995) It is also one of the few to have taken into account both voluntary contract motives (representing reasons for why temporary work is preferred over permanent work) and involuntary contract motives (representing reasons for why temporary work was forced to be accepted although permanent work would be preferred). Furthermore, there are few other studies (for an exception, see Silla et al., 2005) that have related underlying motives and preferences to well-being. 
The results of this rather exploratory study showed that temporary workers tended to choose their contract type based on involuntary (sometimes combined with voluntary) reasons, and that they differed in regard to their levels of work involvement. This finding therefore gives support to the assumption that one's motives for preferring temporary employment or permanent employment may be more complicated than can be captured by simple yes or no answers (Krausz et al., 1995). Individuals may be driven by more than one, and sometimes even contradictory motives (see de Jong et al., in press; Tan \& Tan, 2002). It was also found that work does not necessarily play a less central role in the lives of all workers in alternative employment. This finding is important, since it has occasionally been suggested that workers in alternative employment may have other, more important, life roles (Martin \& Sinclair, 2007; Morris \& Vekker, 2001), which may help buffer against unfavorable work and contract conditions since this area of life is deemed less important (Thorsteinson, 2003). For those who consider work to be a central element in their lives, work may, to a higher extent, serve to satisfy their latent needs as regards, for example, time structure, social contacts outside the family, social status, and identity (Jahoda, 1982). In consequence, these workers may be compelled to take on work even though they dislike the type of contract.

More importantly, the identified patterns corresponded to different reports of work-related and general well-being, which reveals interesting and new insights. Greater well-being was found among those workers whose reasons for taking on temporary work showed a balance between involuntary and voluntary motives or work involvement. This extends the literature that simply has divided contract motives into either voluntary or involuntary, in the current life situation and the future (Krausz, 2000; Krausz et al., 1995). Likewise, it adds to earlier reports that found associations between contract volition - in combination with factors such as employability - and both performance (Marler et al., 2002) and well-being (Silla et al., 2005), respectively. By showing that involuntary reasons for choosing temporary work, when combined with voluntary reasons and/or general work involvement, may have less detrimental effects on well-being, Study II may provide an answer as to why earlier studies have reached contradictory conclusions concerning the links between contract motives and outcomes, for example, in terms of role stress (cf. Krausz, 2000; Krausz et al., 1995) and performance (cf. Ellingson et al., 1998; Tan \& Tan, 2002). The result indicating that involuntary temporary work may be less harmful when work involvement is high seems to give more support to the assumption that work involvement may buffer against the negative consequences of insecurity (see Sverke et al., 2002) than to the assumption that it may make the adjustment to short-term employment, with its potential risk of unemployment, more difficult (as is suggested by unemployment research; see Isaksson et al., 2004). The finding that involuntary temporary work does not necessarily 
imply impaired well-being may also help resolve why the well-being reports of temporary workers may differ even though the statistics frequently show that a majority of temporary work is taken on in spite of an expressed dislike for the contract type (for an overview, see, e.g., Guest, 2004).

In Study II, well-being was most negatively affected among those with consistently 'negative' patterns characterized by predominantly involuntary reasons for temporary work in combination with low work involvement. One possible explanation for this finding may be that those who want a permanent contract may feel compelled to invest energy into showing their engagement and commitment to the employer (P. Virtanen et al., 2002) to succeed in competing for renewed or permanent employment (De Cuyper \& De Witte, 2007). However, such strategies may require more involvement in work than individuals, particularly those who ascribe work a less important role in their lives, feel willing to invest. This discrepancy may be one conceivable explanation for the findings of lower well-being in this group, but this conclusion needs to be validated in further studies.

\section{Preferences for the job versus the contract}

The question over why employees accept their working arrangements constitutes perhaps one of the most relevant but underexplored areas of earlier research (Connelly \& Gallagher, 2004). To address this, Study III explored the associations between individual reactions and job and contract preferences for different types of alternative employment contracts in comparison to permanent full-time work.

Firstly, the findings showed that the formal employment contract had no direct effect on well-being. This result, which contradicts earlier studies that have found contract effects (e.g., Aronsson et al., 2002; M. Virtanen, Kivimäki, Joensuu, et al., 2005), may perhaps be explained by the fact that important demographics were controlled for, which has been demonstrated to partly account for the effects otherwise ascribed to the contract (Bardasi \& Francesconi, 2004). However, contract type was associated with workrelated attitudes, as on-call workers reported less organizational commitment, and all alternative employment groups indicated less intention to quit than permanent full-time employees. This finding may suggest that for alternative employment groups, mechanisms of building loyalty and intentions to stay do not follow patterns similar to those of the permanent workforce (Gallagher \& Sverke, 2005), which typically imply that high commitment is a prerequisite for low turnover intentions (Meyer \& Allen, 1997). Workers in alternative employment may be more apt to generally prioritize securing employment, irrespective of how attached they are to the 
company, for reasons that are related, for example, to their previous experiences of unemployment or low employability. However, these assumptions are still speculative at this point and would need to be explored further, for example, by directly investigating perceived employment prospects (De Cuyper \& De Witte, 2007).

Secondly, subjective variables concerning preferences appeared to be positively related to attitudes and well-being and negatively related to intentions to quit. It needs to be noted here that job preferences revealed more robust relationships than contract preferences did, and that the predictive value of both kinds of preferences together was lower for wellbeing than for attitudes. Thus, Study III suggests that the effects of job preferences may even override those of contract preferences, and they not only seem to affect well-being (as has been reported by Aronsson and Göransson, 1999), but also, and perhaps even more strongly, attitudes towards work. For individuals to have what they would consider to be the wrong job and wrong contract may thus not only lead to subjective health problems and lower life quality, as has been indicated in earlier Swedish studies on locked-in and locked-out effects (Aronsson \& Göransson, 1999; Aronsson et al., 2000), but it may also bring with it organizational costs as well. This finding helps to illustrate the proposed links between individual consequences and effects on employers (Pfeffer, 2000), as such organizational consequences may make employers more prone to act.

Thirdly, and most interestingly, the mechanisms between preferences and outcomes may work in slightly different ways depending on employment contract status. For permanent full-time workers, job preferences do seem to be more relevant than contract preferences for predicting positive outcomes, which is in line with previous findings (Aronsson \& Göransson, 1999; Aronsson et al., 2000). For workers in alternative employment, however, preferences for the contract appear to be somewhat more relevant, and in part, they tend to balance out the disadvantages of having an unpreferred job. From the perspective of labor market theories (e.g., Doeringer \& Piore, 1971) or the stepping-stone motive theory (Korpi \& Levin, 2001), this finding may show that workers' ambitions to establish a more permanent labor market position can take precedence over aspects of job and career aspirations, which are of secondary relevance. Also, the finding may be applicable to high school and college students who use alternative employment as means of earning extra spending money, at a time in their lives when they may not yet be qualified for more interesting and challenging jobs (Loughlin \& Barling, 2001). Similarly, contract preferences may outweigh job preferences for those who seek to gain experience and test different occupational settings before making vocational choices or completing their education (Bernasek \& Kinnear, 1999). The fact that 
contract preferences had a compensating effect for fixed-term and part-time employment, but not for on-call employment, seems to provide more support for the notion that labor market segregation operates in different ways for the groups in the periphery (Kalleberg, 2003).

\section{The importance of perceived job conditions}

Trends towards more flexibilization and individualization may mean that the individuals' control over their employment situation has become an important source for health and well-being, that may have the potential to even override the effect of job qualities and the perceptions of these (e.g. Aronsson \& Göransson, 1999; Kalleberg, 2003). Whereas some scholars have studied perceptions of job insecurity across different employment forms (e.g. De Witte \& Näswall, 2003), surprisingly little research has raised the question what different levels of unpredictability, and thus, control over employment conditions mean for subjective well-being, when compared to the relative impact of differences in perceptions of job characteristics. Study IV is one of the few (for another one, see De Cuyper \& De Witte, 2006) to empirically address this question and includes perceptions of job insecurity as well as perceptions of job control and demand.

When on-call employment, fixed-term employment, and permanent parttime employment were compared to permanent full-time work after controlling for background characteristics, the effects on health complaints were found to be small. Thus, differences in contract type explained little about the consequences on work-related and general well-being. In contrast, perceptions of job conditions - operationalized in terms of control, demands, and job insecurity - were consistently and robustly related to both outcomes, and thus far more relevant predictors. These results suggest that having control in a job situation, as, for example, is suggested by the demandcontrol model (Karasek \& Theorell, 1990), is still more relevant for workers' well-being than facing control and predictability in regard to their employment, which had been assumed to be a factor with increasing relevance in contemporary working life (Aronsson, 2001; Aronsson \& Göransson, 1999; Kalleberg, 2003). This conclusion is furthermore supported by the fact that perceptions of control and demand were equally associated with well-being across all employment groups in this study. This contradicts findings from a Belgian study however, which found that job perceptions of control and demand did relate to the expected positive effects for permanent, although not temporary, employees (De Cuyper \& De Witte, 2006). Their findings seem to fit the assumption that the effects of control in a job become less important when employment terms are uncertain, as this type of situation implies less control over the contract and work as such 
(Aronsson, 2001; Aronsson et al., 2002). However, with respect to the limited empirical evidence at hand, and the differences between the two studies (e.g., in terms of country context, sample differences, operationalization of employment contract types), an important avenue for future research will be to clarify under what circumstances perceptions of the job, as compared to labor market and employment related characteristics, may or may not play a larger role in determining employees' health and well-being.

With respect to perceptions of job insecurity, the picture becomes more clear-cut: Study IV found that with varying employment types, the relationship between job insecurity and well-being may differ. As in other analyses (De Witte \& Näswall, 2003; Mauno et al., 2005; P. Virtanen et al., 2002), job insecurity was found to be detrimental to the well-being of permanent full-time workers. However, previous studies reported no such effect of job insecurity on well-being when simply analyzing all temporary workers together. By going beyond these less refined analyses, Study IV was able to show that the well-being of permanent part-time workers and on-call workers was independent from the level of perceived job insecurity, whereas fixed-term employees' reactions were found to be comparable to those of permanent full-time workers, as their well-being was negatively affected under the condition that they perceived job insecurity.

Study IV thus adds to earlier research by suggesting several conclusions. Firstly, subjective perceptions of the continuance of a job, as compared to 'objective' exposure to a specific employment condition and its inherent levels of uncertainty, seems to be more relevant for understanding individual well-being. Also, it could be demonstrated that differentiating among alternative employment forms enables a better understanding of these consequences. For example, while other research has often looked upon job insecurity as an element of the psychological contract for temporary workers, and not for permanents, in order to explain workers' different reactions (De Witte \& Näswall, 2003; Mauno et al., 2005), this study shows that the underlying mechanisms may be more complex. By disentangling the employment forms, it could be seen that the mechanisms of temporary fixedterm workers were the same as those of permanent full-timers, but different from those of permanent part-time and on-call workers. If the effect is to be explained by psychological contract type, it may be that the psychological contract varies between the different types of alternative employment. For example, it may be that fixed-term workers have another subjective time frame (McLean Parks et al., 1998), or expect to be more permanently employed, which may be another factor influencing their reactions (De Cuyper \& De Witte, 2006). Alternatively, the results may be understood within the framework of the effort-reward imbalance model (Siegrist, 1996); 
when a time dimension is added, some temporary workers, but not others, may accept unfavorable conditions, such as greater perceptions of job insecurity, for a certain amount of time, if they expect to be rewarded in the future (e.g., by being promoted to more secure employment). Still other factors that may explain these different findings are those of volition (McLean Parks et al., 1998) and work involvement (Kanungo, 1982), which may alter the importance of job security for subjective well-being.

\section{Effects of contract heterogeneity}

In all four studies, contracts have been studied in combination with individual differences. Based on the studies, the following conclusions can be drawn. Separating alternative employment contracts into permanent parttime contracts, temporary fixed-term contracts, and temporary on-call contracts and comparing them to permanent full-time arrangements explained the differences in individual well-being only to a limited extent. When it comes to work-related attitudes, differences between on-call employment and permanent full-time work were found in regard to organizational commitment, as were differences in regard to intention to quit when comparing alternative employment forms to permanent full-time contracts, after controlling for background variables.

The results, particularly regarding organizational attitudes, may indicate that those of the primary, as opposed to the secondary, labor market group may compete for employment in different ways (Doeringer \& Piore, 1971). However, since there are differences among those of the secondary segment, the dualism in Doeringer and Piore's (1971) framework appears to be too simplistic. Also, the results do not really fit the idea of a 'first peripheral' group that groups in equal distance around the core as the flexible firm model (Atkinson, 1984) seems to suggest. There was no clear order in which the alternative groups that differed from core full-time work could be ranked, as the core-periphery model would imply (e.g., Aronsson et al., 2002), although the descriptive results of Study III and IV hinted at some marginalization effects for on-call contracts.

However, an interesting finding of the studies in this thesis is that the relevance of contract type emerged through its interaction with individualrelated variables. Contract type together with individual background characteristics was associated with the differences in role stress, attitudes, and well-being found in the first study. In Studies III and IV, the reactions of alternative employment groups in terms of well-being and work-related attitudes differed among each other and also from those of permanent fulltime workers, when their differences in terms of job conditions (job 
insecurity) and job and contract preferences were analyzed simultaneously. What could be shown by differentiating between contracts was that individual differences altered the reactions of permanent workers and temporary workers in different ways. This, again, underscores that dualistic models, which categorize contracts into permanent and temporary contracts or into permanent full-time and alternative contracts, are too simplistic. Earlier speculations that related such findings to a violation of the contract of permanent, but not temporary, workers (e.g., in terms of job insecurity, see De Witte \& Näswall, 2003; Mauno et al., 2005) cannot explain these findings either. Rather, the implication of these findings seems to be twofold. First, contracts need to be differentiated carefully in order to avoid a misinterpretation of results. Second, the contractual and perceptual aspects of employment and labor market status seem to be interrelated, and are thus both relevant to consider in order to better understand the consequences (for a similar conclusion, see P. Virtanen et al., 2002).

\section{Methodological considerations}

As with all empirical research, there are some methodological considerations that need to be commented on more thoroughly, since they too have implications on the findings and their interpretation.

A first issue concerns the samples studied in this thesis. Two different samples were used, which were collected at different points in time, in different organizations, and across different sectors. In Studies I and III, the data comprising health care professionals was taken from a majority of the employees of two large organizations. Thus, while they may be representative for these organizations, and carry the advantage that the occupational settings are held constant when effects of employment- and job-related variables are tested (cf. de Jonge et al., 2001), they may not generalize to all health care personnel. Furthermore, it may also be that health care professionals have high intrinsic motivation and share role characteristics due to their professions (Sverke et al., 2000), which may lead to employees exhibiting more similarities across employment forms or patterns than might occur in a nationwide or non-sector specific sample. Furthermore, the data was collected during a time of organizational change, which may have influenced some of the results (Mishra \& Spreitzer, 1998). However, while it is possible that the absolute levels of, for example, insecurity perceptions may have been affected due to this, the main focus of this thesis was on the relations between variables. Also, with organizational changes often being a common element in today's working world (Sundin \& Wikman, 2004), the circumstances found in this sample may be rather representative for the contemporary workforce, which should strengthen the 
external validity of the findings. The other sample used in this thesis, in Studies II and IV, was collected in 2004, across three different sectors (food industry, education, retail), and from a number of different organizations whose size and ownership varied. Although the sample is not representative for the companies, sectors, or the workforce (in terms of different contracts), it reflects some general trends of the Swedish labor force, relating to, for example, the characteristics of the analyzed contract groups, and the relative distribution of fixed-term and on-call workers (see, e.g., Aronsson et al., 2002; Wikman, 2002). Thus, the sample is rather heterogeneous, which should strengthen the external validity of the findings (e.g., Cook \& Campbell, 1979). However, a replication of the studies would be called for to further test the validity of this thesis's findings in population-based samples.

A second consideration concerns the contracts under study. In this thesis, only two-part relations of alternative employment forms are focused upon, since it was deemed important to understand how these forms would differ from permanent full-time work, and previous empirical evidence was scarce (Connelly \& Gallagher, 2004). However, there are many other forms of alternative work, including that of leased workers from temporary agencies, private consultants, and self-employed, that are a challenge for common work life theories, which often assume employment to be open-ended, dependent, and full time, with one employer (Gallagher \& Sverke, 2005). Furthermore, this thesis has treated part-time workers as one group, but recent evidence shows that even part-time work may include different subgroups (Martin \& Sinclair, 2007). Definitely, more research is needed which includes other contract types and allows for further differentiations in order to enhance our understanding of the nature and implications of contract heterogeneity.

All of the studies here are embedded in the Swedish national context. This characteristic may enhance the possibilities of comparing the studied employment forms and their outcomes, since the different reactions can hardly be ascribed to differences in welfare systems or labor legislation. Also, in general, the European context and the legislation that constitutes a frame for all of its members is regarded as offering relatively secure and fair deals, even in regard to alternative employment forms (De Cuyper et al., 2008), which may influence the results. From a wider perspective, it is possible that these findings are only able to be generalized within modern industrial societies and welfare states, since aspects of uncertainty or unpredictability in alternative employment relations may only take on meaning where they can be compared to a 'standard of permanent employment.' Thus, it appears rather difficult to estimate how replicable the findings are in other countries. Although a recent European study found 
between-country effects to be small when implications of contracts were analyzed (Guest et al., in press), it appears important to further test the relevance of different societal frameworks and national contexts, particularly when differences can be expected to be large.

Furthermore, this thesis has not specifically taken the role of gender into account, although statistics show that temporary and part-time employment is more common among women than men (e.g., see Corral \& Isusi, 2004; OECD, 2002; Wikman, 2002; Wikman et al., 1998). Some efforts have in fact been made to better understand the relation of gender and employment contracts by using both of the data sets in this thesis, but the gender effects were found to be little (see Mohr, Isaksson, \& Rigotti, 2006; Sverke et al., 2000). It is conceivable that the choice of sectors and the study of different organizations brought about a rich variance of contracts, occupational settings, and positions for both men and women, which may have hampered any proper comparative analyses concerning the role of gender. Thus, the question of what effects a gendered labor market, particularly when it comes to alternative employment, can have on men and women still remains to be answered. In this regard, the social constructivist framework (as has been discussed more recently in relation to alternative employment, see e.g., Casey \& Alach, 2004; Marler \& Moen, 2005) may perhaps constitute a fruitful approach for future research.

A restriction that applies to all four studies concerns the very nature of crosssectional designs. The assumed causal relationships between contracts and employee well-being and attitudes and between individual differences and employee well-being and attitudes cannot be tested. Prospective and panel studies, however, have demonstrated that the patterns seem to be complex, allowing the conclusion that marginalized employment forms have subsequent effects on health (M. Virtanen, Kivimäki, Joensuu, et al., 2005). However, the 'healthy worker-effect' has also been discussed, which presumes that the healthiest individuals in the labor market may have the best chances of gaining employment, thus suggesting that the individual's health status prior to taking on alternative employment may additionally influence the results (M. Virtanen, Kivimäki, Elovainio, et al., 2005). Studying associations is, nevertheless, considered worthwhile since finding an association between two indicators is one of the conditions to be met for establishing causality (Bollen, 1989). It is thus considered to be an important step to take before planning longitudinal studies that seek to detect the mechanisms that link contractual arrangements with well-being and morbidity (M. Virtanen, Kivimäki, Joensuu, et al., 2005).

All four studies of this thesis used data collected from self-reports in questionnaires. This may entail two types of problems. Firstly, particularly 
when it comes to dependent measures on health and well-being, there is no possibility to interfere from the results on the 'objective' health status. In other words, self-reports on well-being and health indicators may not necessarily mirror objective situations (Spector, 1994), such as physical symptoms or work ability. There is some evidence, however, that consequences can also manifest as objective health indicators, in that they, for example, can be captured through diagnosed diseases (M. Virtanen et al., 2003). Secondly, although self-reports are the most appropriate type of measurement when subjective preferences, motives, perceptions of job conditions, and well-being are being investigated, there is a risk for common method variance (Campbell \& Fiske, 1959), which may lead to an overestimation of the associations between the variables. To reduce the potential risk of common method variance, suitable questionnaire design techniques (e.g., changing the response format, anonymity, instructing the participants that there are no right or wrong answers) were followed (Podsakoff, MacKenzie, Lee, \& Podsakoff, 2003). Also, in the second and fourth study, and for health complaint measures in the third study, the socalled 'Harman's single-factor test' (loading all variables into an exploratory factor analysis, see Podsakoff et al., 2003) was performed, which suggested a factor structure in line with the key constructs of the studies, and found no evidence of a single or general factor accounting for the majority of the variance.

\section{Implications for future research}

Despite these limitations, this thesis presents findings that are likely to stimulate new questions and further research on alternative employment forms and their consequences. Some of the questions that may be of particular interest are presented in more detail below.

Since the psychological mechanisms of individuals - in their interplay with employment contracts - have appeared to be important predictors in this thesis, more scientific attention should be directed towards the identification of those factors that most influence this interrelationship. As has been noted in earlier reviews (e.g., Connelly \& Gallagher, 2004; De Cuyper et al., 2008), contract volition seems to be a central factor, but this thesis shows that more attention needs to be paid to other aspects of volition, such as those which evolve from the job, or from individuals' views on the centrality of work. Personal life goals, and one's aims and aspirations regarding a current job or a future career may also be important factors to consider. Furthermore, studies that better capture the fit of employment and job to an individual's needs and preferences may further refine our understanding of individual reactions. Although it may be rather complex in scope, personal 
and work-related background factors may serve as an important complement in such analysis, since changing life roles and life span events may alter what individuals need most from their employment and, more specifically, from their jobs (Huang, 2006). In addition, individual factors concerning personality may be an important area to explore in order to better understand employees' reactions in different employment situations and jobs. For example, it has been shown that individuals with a more internal locus of control report better mental health than those with an external control locus in circumstances containing high levels of job insecurity (Näswall, Sverke, \& Hellgren, 2005). It appears conceivable that such mechanisms also play a role in how contractual conditions are perceived and coped with, affecting the degree of uncertainty and unpredictability experienced in the situation.

The results of this thesis imply that a differentiation among alternative employment contracts is warranted, but it is clear that more efforts are needed if we are to eventually explain when and why individuals in different employment groups show different reactions. Besides the role of individual differences, shifts in individuals' perceptions of the employment standards may also affect the results. Some scholars have noted that the newest generation of workers may have values and expectations that differ from their predecessors (Loughlin \& Barling, 2001). It has also been argued that the standard of permanent full-time work may undergo erosion in certain circumstances, such as after dismissals have taken place in connection with organizational downsizing (Mishra \& Spreitzer, 1998) or when there is an increased use of temporary workers (De Cuyper et al., 2008). Likewise, the conditions of alternative employment contracts may have changed over the years, for example, due to improvements based on more recent antidiscrimination regulations, such as the EU equal treatment act (Vigneau, Ahlberg, Bercusson, \& Brunn, 1999). More advanced methods, such as more complex longitudinal or cohort designs, as well as the use of retrospective analysis, may be useful for investigating how these changes influence the research results which may eventually affect public policies.

In addition to the formal employment contract, another relevant research area concerns the psychological contract (Rousseau, 1995), the unspoken agreement between employer and employee (Conway \& Briner, 2005), which often holds the expectations against which the actual contract is evaluated. Following this logic, it is not only the actual contract conditions and differences between them, but also the individual perceptions of the contractual terms, their perceived overall fairness and justice (Conway \& Briner, 2005), and the degree to which they are fulfilled that impacts the employee's attitudes, behavior (McLean Parks et al., 1998) and well-being (Guest et al., in press). While research has begun to relate psychological contracts to permanent and temporary or part-time work (Connelly \& 
Gallagher, 2004), the investigations have generally not delved very deeply into, for example, the differences among temporary employment forms and their related consequences. Little is also known about how perceptions of psychological contracts are affected by individual differences, such as those relating to background, previous employment experience, and career goals and aims.

Another avenue for future studies concerns the associations between individual and organizational effects, as little is known about how effective and cost-reducing the use of different employment forms really is (Bergström \& Storrie, 2003). To better understand the mechanisms that relate individual perceptions and consequences to organizational characteristics and outcomes is considered to be important for at least two reasons. Firstly, it would test the assumption that costs and benefits stand and fall in conjunction with the consequences brought about because of employment forms. Secondly, and relatedly, it may likely provide information that could be used in some way to facilitate the practical management of a blended workforce (Broschak \& Davis-Blake, 2006). Such an interactionist analysis may also be beneficial for a better understanding of how organizations as well as individuals perceive the growing use of flexibility (Reilly, 1998), their contemporary forms of contracting with each other (Raeder \& Grote, 2005), and the potential effects for both parties (Guest et al., in press).

\section{Concluding remarks}

This thesis has set out to increase our knowledge about alternative employment forms and their effects on the individual. As has been outlined in the introduction to this thesis, a plethora of employment forms has emerged over the past decades, which has raised the question, in the research community and the public, of what the potential implications are of this development both for the individual and the companies. Thus far, the scientific evidence has been mixed, but based on previous investigations, two tenets were followed in this thesis. Firstly, to differentiate among the various alternative employment forms was important, since their heterogeneous nature suggested that their consequences may differ. Secondly, as alternative employment forms have become a reality for an increasingly more diverse group of workers, a focus was put on their background differences and perceptions in order to try to determine what implications the studied alternative employment forms have for individuals.

In general, the results of the studies support these two tenets. More can be learned about employees' well-being and work-related attitudes when 
contract heterogeneity is analyzed along with individual differences. The overall conclusion of this thesis is that the specific conditions of an employment arrangement, together with the perceptions arising from the needs and goals of the individual, as they relate to one's current life situation and job circumstances, are critical aspects to consider for better understanding the consequences. This, however, does not imply that contracts do not matter and that the outcomes - in terms of personal health, well-being, attitudes and behavior - are entirely up to the individual, who would then only have to somehow develop the 'right' perceptions and 'appraisal' towards his or her situation. It is critical that future research on alternative employment continues to look at the interactive effects of contracts and individuals, and especially the nature of what comprises the individual and contractual circumstances that may lead to positive as opposed to negative reactions. Such research should help guide the development of appropriate preventive measures.

Of interest for the public discussion, particularly HR management and unions, is the fact that alternative employment forms cannot per se be presumed to be entirely good or bad for the workforce. Rather, some contracts may be more suitable than others in a given situation or for a specific person, since the potential consequences are likely to differ between groups and between individuals. To date, the legislative frameworks of the EU and its member states are fairly protective compared to other industrialized nations, and this perhaps relates to the findings that employment forms as such had no overall dramatic effect, but instead, the variance is explained by the finer interactions between individuals and their contract terms. On the other hand, it may be that over time, employees are able to adjust to the changing working world, which thus leads to less negative reactions. To further validate any of these possible explanations and their implications for legislative frameworks, suitable levels of protection in terms of employment contracts and human resource management principles need to be researched and evaluated along with existing employment strategies and their long-term consequences.

While radical forecasts have predicted the end of permanent work, labor market statistics of recent years have reported that the dramatic growth of alternative employment forms that took place at the end of the 1980s and mid 1990s in many western industrial societies has leveled off. This may imply that although alternative employment has come here to stay, it may not be able to fully substitute the permanent full-time workforce. It may also indicate that for any type of flexibility, there needs to be some stability to balance turbulent environments. Given this assumption, it appears rather likely that heterogeneous forms of employment will coexist since they fill different roles for organizations. Likewise, on an individual level, alternative 
employment forms may fill important functions, such as providing workers with the opportunity to test different roles, to gather experience in different occupational settings, and to adjust their employment commitments according to their varying needs over a lifespan. However, to better understand in what way different employment forms can ease transitions, instead of becoming dead-end streets, and to generate more knowledge about what constitutes stability or security for individuals in modern working life, further research will be needed.

Finally, it also needs to be kept in mind that the definition of what constitutes a standard employment form has changed in the past and will most likely change again in the future. The consequences of using a more differentiated workforce, which on the individual level entails more disrupted working careers may be better understood in relation to different generations' perceptions and evaluations of standard employment, which continually sets the backdrop against which the 'alternatives' are judged. 


\section{References}

Abrahamsson, B. (1993). Why organizations? How and why people organize. Newbury Park: Sage Publications.

Aiken, L. S., \& West, S. G. (1991). Multiple regression: Testing and interpreting interactions. London: Sage Publications.

Alexandrov, A., Babakus, E., \& Yavas, U. (2007). The effects of perceived management concern for frontline employees and customers on turnover intentions. Journal of Service Research, 9(4), 356-371.

Allan, C., Brosnan, P., Horwitz, F., \& Walsh, P. (2001). From standard to non-standard employment. International Journal of Manpower, 22(7/8), 748-763.

Allan, P. (2002). The contingent workforce: Challenges and new directions. American Business Review, 20(2), 103-110.

Allen, N. J., \& Meyer, J. P. (1990). The measurement and antecedents of affective, continuance and normative commitment to the organisation. Journal of Occupational Psychology, 63(1), 1-18.

Allvin, M., Aronsson, G., Hagström, T., Johansson, G., \& Lundberg, U. (2006). Gränslöst arbete: Socialpsykologiska perspektiv på det nya arbetslivet [Boundaryless work: Socialpsychological perspective on the new world of working]. Malmö: Liber.

Aronsson, G. (1999). Contingent work and health and safety. Work, Employment \& Society, 13(3), 439-459.

Aronsson, G. (2001). A new employment contract. Scandinavian Journal of Work, Environment and Health, 27(6), 361-364.

Aronsson, G., Dallner, M., \& Gustafsson, K. (2000). Yrkes- och arbetsplatsinlåsning En empirisk studie av omfattning och hälsokonsekvenser [Being locked-in in occupation and workplace: An empirical study of prevalence and health consequences]. Arbete och Hälsa, 2000:5.

Aronsson, G., Dallner, M., Lindh, T., \& Göransson, S. (2005). Flexible pay but fixed expenses: Personal financial strain among on-call employees. Internal Journal of Health Services, 35(3), 499-528.

Aronsson, G., \& Gustafsson, K. (1999). Kritik eller tystnad: En studie av arbetsmarknads- och anställningsförhållandens betydelse för arbetsmiljökritik [Critics or silence: A study about the impact of labor market position and employment status on critics of work environment matters]. Arbetsmarknad \& Arbetsliv, 5(3), 189-206. 
Aronsson, G., Gustafsson, K., \& Dallner, M. (2002). Work environment and health in different types of temporary jobs. European Journal of Work and Organizational Psychology, 11(2), 151-175.

Aronsson, G., \& Göransson, S. (1999). Permanent employment but not in a preferred occupation: Psychological and medical aspects, research implications. Journal of Organisational Health Psychology, 4(2), 152-163.

Artazcoz, L. L., Borrell, C., Benach, J., Cortès, I., \& Rohlfs, I. (2004). Women, family demands and health: The importance of employment status and socio-economic position. Social Science \& Medicine, 59(2), 263-274.

Ashford, S. J., Lee, C., \& Bobko, P. (1989). Content, causes, and consequences of job insecurity: A theory-based measure and substantive test. Academy of Management Journal, 32(4), 803-829.

Atkinson, J. (1984). Manpower strategies for flexible organisations. Personnel management, 16(8), 28-31.

Baltes, P. B., \& Nesselroade, J. R. (1979). History and rationale of longitudinal research. In J. R. Nesselroade \& P. B. Baltes (Eds.), Longitudinal research in the study of behavior and development (pp. 1-39). New York: Academic Press.

Bardasi, E., \& Francesconi, M. (2004). The impact of atypical employment on individual wellbeing: Evidence from a panel of British workers. Social Science \& Medicine, 58(9), 1671-1688.

Barker, K., \& Christensen, K. (1998). Contingent work: American employment relations in transition. Ithaca: Cornell University Press.

Barling, J., \& Gallagher, D. G. (1996). Part-time employment. In C. L. Cooper \& I. T. Robertson (Eds.), International review of industrial and organizational psychology (Vol. 11, pp. 243-277). New York: Wiley.

Beard, K., M., \& Edwards, J. R. (1995). Employees at risk: Contingent work and the psychological experiences of contingent workers. In C. L. Cooper \& I. T. Robertson (Eds.), Trends in organizational behavior (Vol. 2, pp. 109-126). New York: Wiley.

Beck, U. (2000). The brave new world of work. Cambridge: Polity Press.

Beehr, T. A., Walsh, J. T., \& Taber, T. D. (1976). Relationship of stress to individually and organizationally valued states: Higher order needs as a moderator. Journal of Applied Psychology, 61(1), 41-47.

Bellaagh, K., \& Isaksson, K. (1999). Uthyrd men fast anställd [Hired out, but permanently employed] Arbete \& Hälsa, 1999:6.

Benach, J., Benavides, F. G., Platt, S., Diez-Roux, A., \& Muntaner, C. (2000). The health-damaging potential of new types of flexible employment: A challenge for public health researchers. American Journal of Public Health, 90(8), 1316-1317.

Bergman, L. B., Eklund, G., \& Magnusson, D. (1991). Studying individual development: Problems and methods. In D. Magnusson, L. B. 
Bergman, G. Rudinger, \& B. Törestad (Eds.), Problems and methods in longitudinal research: Stability and change (pp. 1-27). Cambridge: Cambridge University Press.

Bergman, L. B., \& Magnusson, D. (1997). A person-oriented approach in research on developmental psychopathology. Development and Psychopathology, 9(2), 291-319.

Bergman, L. B., Magnusson, D., \& El-Khouri, B. M. (2003). Studying individual development in an interindividual context: A personoriented approach. Mahwah, N.J.: Lawrence Erlbaum Associates.

Bergström, O. (2001). Externalization of employees: Thinking about going somewhere else. International Journal of Human Resource Management, 12(3), 373-388.

Bergström, O. (2002, July). Why does the use of contingent employment differ between industries? Investigating institutional processes in the European food industry. Paper presented at the 18th EGOS Colloquium on Organizational politics and the Politics of Organizations, Barcelona, Spain.

Bergström, O., \& Storrie, D. (2003). Contingent employment in Europe and the United States. Cheltenham: Edward Elgar.

Bernasek, A., \& Kinnear, D. (1999). Workers' willingness to accept contingent employment. Journal of Economic Issues, 33(2), 461469.

Bernhard-Oettel, C., \& Isaksson, K. (2005). Work-related well-being and job characteristics among temporary workers in Sweden. In N. De Cuyper, K. Isaksson, \& H. De Witte (Eds.), Employment contracts and well-being among European workers (pp. 177-200). Aldershot: Ashgate.

Biggs, D., Burchell, B., \& Millmore, M. (2006). The changing world of the temporary worker: The potential HR impact of legislation. Personnel Review, 35(2), 191-206.

Bollen, K. A. (1989). Structural equations with latent variables. New York: Wiley.

Broschak, J. P., \& Davis-Blake, A. (2006). Mixing standard work and nonstandard deals: The consequences of heterogeneity in employment arrangements. Academy of Management Journal, 49(2), 371-393.

Bryson, C., \& Blackwell, R. (2006). Managing temporary workers in higher education: Still at the margin? Personnel Review, 35(2), 207-224.

Burchell, B., Lapido, D., \& Wilkinson, F. (2002). Job insecurity and work intensification. London: Routledge.

Buttram, R. T. (1996). Working without a net: A theoretical and empirical analysis of worker responses to temporary work. Unpublished doctoral dissertation, Tulane University. 
Campbell, D. T., \& Fiske, D. W. (1959). Convergent and discriminant validation by the multi-trait-multimethod matrix. Psychological Bulletin, 56(2), 81-105.

Caplan, R. D. (1971). Organizational stress and individual strain: A socialpsychological study of risk factors in coronary heart diseases among administrators, engineers, and scientists. Ann Arbor, Michigan: Institute of Social Research, University of Michigan, University Microfilms No 72/14822.

Casey, C., \& Alach, P. (2004). 'Just a temp'? Women, temporary employment, and lifestyle. Work, Employment \& Society, 18(3), 459-480.

Castells, M. (1998). Informationsåldern, ekonomi, samhälle och kultur: Nätverksamhällets framväxt. [Information age, economy, society, and culture: The emergence of a network society]. Göteborg: Daidalos.

Chambel, M., \& Castanheira, F. (2006). Different temporary work status, different behaviors in organization. Journal of Business \& Psychology, 20(3), 351-367.

Cheng, G. H. L., \& Chan, D. K. S. (2008). Who suffers more from job insecurity? A meta-analytic review. Applied Psychology: An International Review, 57(2), 272-303.

Christensen, T., \& Laegreid, P. (2000). New public management: The transformation of ideas and practice. Aldershot: Ashgate.

Clinton, M., Guest, D., Budjanovcanin, A., Staynvarts, N., Krausz, M., \& Bernhard-Oettel, C., et al. (2005). Investigating individual and organizational determinants of the psychological contract: Data collection and analysis. Unpublished report, London: King's College.

Cohany, S. R., Hipple, S. F., Nardone, T. J., Polivka, A. E., \& Stewart, J. C. (1998). Counting the workers: Results of a first survey. In K. Barker \& K. Christensen (Eds.), Contingent work: American employment relations in transition (pp. 41-68). Ithaca: Cornell University Press.

Cohen, J., Cohen, P., West, S. G., \& Aiken, L. S. (2003). Applied multiple regression/correlation analysis for the behavioural sciences (3rd ed.). Mahwah, N.J.: Lawrence Erlbaum Associates.

Connelly, C. E., \& Gallagher, D. G. (2004). Emerging trends in contingent work research. Journal of Management, 30(6), 959-983.

Conway, N., \& Briner, R. B. (2002). Full-time versus part-time employees: Understanding the links between work status, the psychological contract, and attitudes. Journal of Vocational Behavior, 61(2), 279301.

Conway, N., \& Briner, R. B. (2005). Understanding psychological contracts at work: A critical evaluation of theory and research. Oxford: Oxford University Press. 
Cook, J., \& Wall, T. (1980). New work attitude measures of trust, organizational commitment and personal need non-fulfillment. Journal of Occupational Psychology, 53(1), 39-52.

Cook, T. D., \& Campbell, D. T. (1979). Quasi-experimentation: Design \& analysis issues for field settings. Boston, MA: Houghton Mifflin.

Corral, A., \& Isusi, I. (2004). Part-time work in Europe. Dublin: European Foundation for the Improvement of Living and Working Conditions

De Cuyper, N., de Jong, J., De Witte, H., Isaksson, K., Rigotti, T., \& Schalk, R. (2008). Literature review of theory and research on the psychological impact of temporary employment: Towards a conceptual model. International Journal of Management Reviews, 10(1), 25-51.

De Cuyper, N., \& De Witte, H. (2006). Autonomy and workload among temporary workers: Their effects on job satisfaction, organizational commitment, life satisfaction, and self-rated performance. International Journal of Stress Management, 13(4), 441-459.

De Cuyper, N., \& De Witte, H. (2007). Associations between contract preferences and attitudes, well-being and behavioural intentions of temporary workers. Economic and Industrial Democracy, 28(2), 292-312.

De Cuyper, N., Isaksson, K., \& De Witte, H. (2005). Employment contracts and well-being among European workers. Aldershot: Ashgate.

de Jong, J., De Cuyper, N., De Witte, H., Silla, I., \& Bernhard-Oettel, C. (in press). Motives for accepting temporary employment: A typology of temporary workers. International Journal of Manpower.

de Jonge, J., Dormann, C., Janssen, P. M. P., Dollard, M.-F., Landeweerd, J. A., \& Nijhuis, F. J. N. (2001). Testing reciprocal relationships between job characteristics and psychosocial well-being. Journal of Occupational and Organizational Psychology, 74(1), 29-46.

De Witte, H., \& Näswall, K. (2003). Objective versus subjective job insecurity: Consequences of temporary work for job satisfaction and organizational commitment in four European countries. Economic and Industrial Democracy, 24(2), 149-188.

Diener, E., Suh, E. M., Lucas, R. E., \& Smith, H. L. (1999). Subjective wellbeing: Three decades of process. Psychological Bulletin, 125(2), 276-302.

DiNatale, M. (2001). Characteristics of and preference for alternative work arrangements. Monthly Labor Review (March), 28-49.

Doeringer, P. B., \& Piore, M. J. (1971). Internal labour markets and manpower analysis. Lexington, MA: Heath Lexington Books.

Dooley, D. (2003). Unemployment, underemployment, and mental health: Conceptualizing employment status as continuum. American Journal of Community Psychology, 32(1/2), 9-20.

Eberhardt, B. J., \& Shani, A. B. (1984). The effects of full-time versus parttime employment status on attitudes towards specific organizational 
characteristics and overall job satisfaction. Academy of Management Journal, 27(4), 893-900.

Ellingsäter, A. L., \& Ronsen, M. (1996). The dual strategy: Motherhood and the work contract in Scandinavia. European Journal of Population, 12(3), 239-260.

Ellingson, J. E., Gruys, M. L., \& Sackett, P. R. (1998). Factors related to the satisfaction and performance of temporary employees. Journal of Applied Psychology, 83(6), 913-921.

Endler, N., \& Magnusson, D. (1976). Toward an interactional psychology of personality. Psychological Bulletin, 83(5), 956-974.

European Foundation (1996). Precarious employment and working conditions in the European Union. Dublin: European Foundation for the Improvement of Living and Working Conditions in Europe.

Feldman, D. C. (1995). Managing part-time and temporary employment relationships: Individual needs and organizational demands. In M. London (Ed.), Employees, careers, and job creation: Developing growth oriented human resource strategies and programs (pp. 121141). San Francisco: Jossey-Bass/Pfeiffer.

Ferlie, E., Ashburner, L., Fitzgerald, L., \& Pettigrew, A. (1996). The new public management in action. Oxford: Oxford University Press.

Gagliarducci, S. (2005). The dynamics of repeated temporary jobs. Labour Economics, 12(4), 429-448.

Gallagher, D. G., \& McLean Parks, J. (2001). I pledge thee my troth... contingently commitment and the contingent work relationship. Human Resource Management Review, 11(3), 181-208.

Gallagher, D. G., \& Sverke, M. (2005). Contingent employment contracts: Are existing employment theories still relevant? Economic and Industrial Democracy, 26(2), 181-203.

Gallie, D., White, M., Cheng, Y., \& Tomlinsson, M. (1998). Restructuring the employment relationship. Oxford: Oxford University Press.

Gaspirani, G. (2006). Full-time or part-time work: Realities and options. Dublin: European Foundation for the Improvement of Living and Working Conditions in Europe.

Goldberg, D. (1979). Manual of the General Health Questionnaire. Windsor: National Foundation for Educational Research.

Goudswaard, A., \& Andries, F. (2002). Employment status and working conditions. Luxembourg: Office for Official Publications of the European Communities.

Guest, D. (2004). Flexible employment contracts, the psychological contract and employee outcomes: An analysis and review of the evidence. International Journal of Management Reviews, 5/6(1), 1-19.

Guest, D., \& Conway, N. (1998). Fairness at work and the psychological contract. Unpublished manuscript, London: Chartered Institute of Personnel Development. 
Guest, D., Isaksson, K., \& De Witte, H. (in press). Employment contracts, psychological contracts, and worker well-being: An international study. Oxford: Oxford University Press.

Guest, D. E., Oakley, P., Clinton, M., \& Budjanovcanin, A. (2006). Free or precarious? A comparison of the attitudes of workers in flexible and traditional employment contracts. Human Resource Management Review, 16(2), 107-124.

Hartley, J., Jacobson, D., Klandermans, B. \& van Vuuren, T. (1991). Job insecurity. Coping with jobs at risk. Thousand Oaks, CA: Sage Publications.

Heinz, W. R. (2003). From work trajectories to negotiated careers: The contingent life course. In J. T. Mortimer \& M. J. Shanahan (Eds.), Handbook of the lifecourse (pp. 185-204). New York: Kluwer.

Hellgren, J., Sjöberg, A., \& Sverke, M. (1997). Intention to quit: Effects of job satisfaction and job perceptions. In F. Avallone, J. Arnold, \& K. De Witte (Eds.), Feelings work in Europe (pp. 415-423). Milano: Guerini.

Hoffmann, E., \& Walwei, U. (1998). Normalarbeitsverhältnis: ein Auslaufmodell? [Regular employment relationship - a discontinued model?]. Mitteilungen aus der Arbeitsmarkt und Berufsforschung, 31(3), 409-425.

Holmlund, B., \& Storrie, D. (2002). Temporary work in turbulent times: The Swedish experience. The Economic Journal, 112(480), F245-F269.

House, R. J., \& Rizzo, J. R. (1972). Role conflict and ambiguity as critical variables in a model of organizational behaviour. Organizational Behavior and Human Performance, 7(3), 467-505.

Huang, Q. (2006). The nature of women's career development: Determinants and consequences of career paths. Unpublished doctoral dissertation, Stockholm University.

Håkansson, K. (2001). Språngbräda eller segmentering? En longitudinell studie av tidsbegränsat anställda [Stepping stone or dead-end street: A longitudinal study of temporary employees]. Unpublished manuscript, Göteborg: IFAU.

Härenstam, A., Karlqvist, L., Bodin, L., Nise, G., Schéele, P., \& the Moa Research Group. (2003). Patterns of working and living conditions: A holistic, multivariate approach to occupational health studies. Work \& Stress, 17(1), 73-92.

Isaksson, K. (1990). A longitudinal study of the relationship between frequent job change and psychological well-being. Journal of Occupational Psychology, 63(4), 297-308.

Isaksson, K., Aronsson, G., Bellaagh, K., \& Göransson, S. (2001). Att ofta byta arbetsplats - En jämförelse mellan uthyrda och korttidsanställda [To change work place often: A comparison of temporary agency workers and short-term employees]. Arbete och Hälsa, 2001:7. 
Isaksson, K., \& Bellaagh, K. (2002). Health problems and quitting among female "temps". European Journal of Work and Organizational Psychology, 11(1), 27-45.

Isaksson, K., \& Johansson, G. (1997). Avtalspension med vinst och förlust [Gains and losses of early retirement]. Stockholm: Folksam.

Isaksson, K., Johansson, G., Bellaagh, K., \& Sjöberg, A. (2004). Work values among the unemployed: Changes over time and some gender differences. Scandinavian Journal of Psychology, 45(3), 207-214.

Jahoda, M. (1982). Employment and unemployment: A social-psychological analysis. Cambridge, MA: Cambridge University Press.

Kalleberg, A. L. (2003). Flexible firms and labor market segmentation. Work \& Occupations, 30(2), 154-175.

Kanungo, R. N. (1982). Measurement of job and work involvement. Journal of Applied Psychology, 67(3), 341-349.

Karasek, R., \& Theorell, T. (1990). Healthy work: Stress, productivity, and the reconstruction of working life. New York: Basic Books.

Katz, D., \& Kahn, R. L. (1978). The social psychology of organizations (2nd ed.). New York: Wiley.

Kets de Vries, M. F. R., \& Balazs, K. (1997). The downside of downsizing. Human Relations, 50(1), 11-50.

Kjellberg, A. (2001). Fackliga organisationer och medlemmar i dagens Sverige [Union organizations and members in Sweden today]. Lund: Arkiv Förlag.

Kochan, T. A., Smith, M., Wells, J. C., \& Rebitzer, J. B. (1994). Human resource strategies and contingent workers: The case of safety and health in the petrochemical industry. Human Resource Management, 33(1), 55-77.

Korpi, T., \& Levin, H. (2001). Precarious footing: Temporary work as a stepping zone out of unemployment in Sweden. Work, Employment \& Society, 15(1), 127-148.

Krausz, M. (2000). Effects of short- and long term preference for temporary work upon psychological outcomes. International Journal of Manpower, 21(8), 635-647.

Krausz, M., Brandwein, T., \& Fox, S. (1995). Work attitudes and emotional responses of permanent, voluntary, and involuntary temporary-help employees: An exploratory study. Applied Psychology: An International Review, 144(3), 217-232.

Krausz, M., Sagie, A., \& Bidermann, Y. (2000). Actual and preferred work schedules and scheduling control as determinants of job-related attitudes. Journal of Vocational Behavior, 56(1), 1-11.

Kylin, C. (2007). Coping with boundaries: A study on the interaction between work and non-work life in home-based telework. Unpublished doctoral dissertation, Stockholm University.

Lazarus, R. S., \& Folkman, S. (1984). Stress, appraisal, and coping. New York: Springer. 
Letourneux, V. (1998). Precarious employment and working conditions in the European Union. Dublin, Ireland: European Foundation for the Improvement of Living and Working Conditions.

Loughlin, C., \& Barling, J. (2001). Young workers' work values, attitudes, and behaviours. Journal of Occupational \& Organizational Psychology, 74(4), 543-558.

Magnusson, D. (1998). The logic and implications of a person-oriented approach. In R. B. Cairns, L. B. Bergman \& J. Kagan (Eds.), Methods and models for studying the individual (pp. 33-64). Thousand Oaks, CA: Sage Publications.

Marler, J. H., \& Moen, P. (2005). Alternative employment arrangements: A gender perspective. Sex Roles, 52(5-6), 337-349.

Marler, J. H., Woodard Barringer, M., \& Milkovich, G. T. (2002). Boundaryless and traditional contingent employees: Worlds apart. Journal of Organizational Behavior, 23(4), 425 - 453.

Martens, M. F. J., Nijhuis, F. J. N., van Boxtel, M. P. J., \& Knottnerus, J. A. (1999). Flexible work schedules and mental physical health. A study of a working population with non-traditional working hours. Journal of Organizational Behavior, 20(1), 35-46.

Martin, J. E., \& Sinclair, R. R. (2007). A typology of the part-time workforce: Differences on job attitudes and turnover. Journal of Occupational \& Organizational Psychology, 80(2), 301-319.

Mauno, S., Kinnunen, U., Mäkikangas, A., \& Nätti, J. (2005). Psychological consequences of fixed-term employment and perceived job insecurity among health care staff. European Journal of Work and Organizational Psychology, 14(3), 209-237.

McLean Parks, J., Kidder, D. L., \& Gallagher, D. G. (1998). Fitting square pgs into round holes: Mapping the domain of contingent work arrangements onto the psychological contract. Journal of Organizational Behavior, 19(S1), 697-730.

Menéndez, M., Benach, J., Muntaner, C., Amable, M., \& O’Campo, P. (2007). Is precarious employment more damaging to women's health than men's? Social Science \& Medicine, 64(4), 776-781.

Meyer, J. P., \& Allen, N. J. (1997). Commitment in the workplace: Theory, research, and application. Thousand Oaks, CA: Sage Publications.

Mishra, A. K., \& Spreitzer, G. M. (1998). Explaining how survivors respond to downsizing: The roles of trust, empowerment, justice and work redesign. Academy of Management Review, 23(3), 567-588.

Mohr, G., Isaksson, K., \& Riggotti, T. (2006, July). Gender differences in reaction to temporary contracts: The role of psychological contracts. Paper presented at the $26^{\text {th }}$ International Congress of Applied Psychology, Athens, Greece.

Mohr, G., Mueller, A., Rigotti, T., Aycan, Z., \& Tschan, F. (2006). The assessment of psychological strain in work contexts. European Journal of Psychological Assessment, 22(3), 198-206. 
Morris, M. D. S., \& Vekker, A. (2001). An alternative look at temporary workers, their choices, and the growth in temporary employment. Journal of Labor Research, 22(2), 373-390.

Morrison, D., Payne, R. L., \& Wall, T. D. (2003). Is job a viable unit of analysis? A multilevel analysis of demand-control-support models. Journal of Occupational Health Psychology, 8(3), 209-219.

Neugart, M., \& Storrie, D. (2006). The emergence of temporary work agencies. Oxford Economic Papers, 58(1), 137-156.

Nollen, S. D. (1996). Negative aspects of temporary employment. Journal of Labor Research, 17(4), 567-582.

Nollen, S. D., \& Axel, H. (1998). Benefits and costs to employers. In K. Barker \& K. Christensen (Eds.), Contingent work (pp. 126-143). Ithaca: Cornell University Press.

Näswall, K., \& De Witte, H. (2003). Who feels insecure in Europe? Predicting job insecurity from background variables. Economic and Industrial Democracy, 24(2), 189-215.

Näswall, K., Sverke, M., \& Hellgren, J. (2005). The moderating role of personality characteristics on the relationship between job insecurity and strain. Work \& Stress, 19(1), 37-49.

OECD. (1999). Employment Outlook. Paris: Organization for Economic Cooperation and Development.

OECD. (2002). Employment outlook. Paris: Organization for Economic Cooperation and Development.

Öhrming, J., \& Sverke, M. (2001). Bolagiseringen av S:t Göran: En proaktiv organisering. [Hospital corporatization: Proactive organization]. Lund: Studentlitteratur.

Paoli, P., \& Merllié, D. (2001). Third European Survey on Working Conditions. Dublin: European Foundation for the Improvement of Living and Working Conditions.

Particelli, M. C. (1990). A global arena. Journal of Consumer Marketing, 7(4), 43-52.

Pfeffer, J. (2000). Flexibilitet på arbetsmarknaden: Vet företagen verkligen bäst? [Labor market flexibility: Do companies really know best?]. In L. Lennerlöf (Ed.), Avveckla eller utveckla? En antologi om verksamhetskonsekvenser i magra organisationer (pp. 15-35). Stockholm: Rådet för arbetslivsforskning.

Pfeffer, J., \& Baron, J. N. (1988). Taking the workers back out: Recent trends in the structuring of employment. In L.L. Cummings \& B.M. Staw (Eds.), Research in Organizational Behavior (Vol. 10, pp. 257303). Greenwich, CT: JAI Press.

Podsakoff, P. M., MacKenzie, S. B., Lee, J.-Y., \& Podsakoff, N. P. (2003). Common method biases in behavioral research: A critical review of the literature and recommended remedies. Journal of Applied Psychology, 88(5), 879-903. 
Posthuma, R. A., Campion, M. A., \& Vargas, A. L. (2005). Predicting counterproductive performance among temporary workers: A note. Industrial Relations, 44(3), 550-554.

Price, J. L. (1997). Handbook of organizational measurement. International Journal of Manpower, 18(4_5_6), 305-558.

Probst, T. M., \& Brubaker, T. L. (2001). The effects of job insecurity on employee safety outcomes: Cross sectional and longitudinal explorations. Journal of Occupational Health Psychology, 6(2), 139159.

Raeder, S., \& Grote, G. (2005). Neue psychologische Verträge [New psychological contracts]. In D. Frey, L. v. Rosenstiel \& C. G. Hoyos (Eds.), Handbuch für Angewandte Psychologie, Band II, Wirtschaftspsychologie (S. 304-309). Weinheim: Beltz.

Reilly, P. A. (1998). Balancing flexibility: Meeting the interests of employee and employer. European Journal of Work and Organizational Psychology, 7(1), 7-22.

Rifkin, J. (1995). The end of work. New York: Putnam.

Rizzo, J. R., House, R. J., \& Lirtzman, S. I. (1970). Role conflict an ambiguity in complex organizations. Administrative Science Quarterly, 15(2), 150-163.

Roberts, J. H. (2000). Developing new rules for new markets. Journal of the Academy of Marketing Science, 28(1), 31-44.

Rousseau, D. M. (1995). Psychological contracts in organizations: Understanding written and unwritten agreements. Thousand Oaks, CA: Sage Publications.

Ryff, C. (1989). Happiness is everything, or is it? Explorations on the meaning of psychological well-being. Journal of Personality and Social Psychology, 57(6), 1069-1081.

Saloniemi, A., Virtanen, P., \& Vahtera, J. (2004). The work environment in fixed-term jobs: Are poor psychosocial conditions inevitable? Work, Employment \& Society, 18(1), 193-208.

Shanahan, M. J. (2000). Pathways to adulthood in changing societies: Variability and mechanisms in life course perspective. Annual Review of Sociology, 26(1), 667-692.

Siegrist, J. (1996). Adverse health effects of high-effort/low-reward conditions. Journal of Occupational Health Psychology 1(1), 27-41.

Silla, I., Gracia, F. J., \& Peiró, J. M. (2005). Job insecurity and health-related outcomes among different types of temporary workers. Economic and Industrial Democracy, 26(1), 89-117.

Sjöberg, A., \& Sverke, M. (2000). The interactive effect of job involvement and organizational commitment on job turnover revisited: A note on the mediation role of turnover intention. Scandinavian Journal of Psychology, 41(3), 247-252. 
Spector, P. E. (1994). Using self-report questionnaires in OB research: A comment on the use of a controversial method. Journal of Organizational Behavior, 15(5), 385-392.

Sullivan, M., Karlsson, J., \& Ware, J. E. (1995). The Swedish SF-36 Health Survey: I. evaluation of data quality, scaling assumptions, reliability and construct validity across general populations in Sweden. Social Science \& Medicine, 41(10), 1349-1358.

Sundin, E., \& Wikman, A. (2004). Changes in working life and new forms of production. In R. Gustafsson \& I. Lundberg (Eds.), Worklife and health in Sweden 2004 (pp. 11-38). Stockholm: National Institute for Working Life.

Sverke, M., Hellgren, J., \& Gallagher, D. G. (2000). Alternative work arrangements: Job stress, well-being, and work attitudes among employees with different employment contracts. In K. Isaksson, L. Hogstedt, C. Eriksson, \& T. Theorell (Eds.), Health effects of the new labour market (pp. 145-167). New York: Plenum.

Sverke, M., Hellgren, J., \& Näswall, K. (2002). No security: A meta-analysis and review of job insecurity and its consequences. Journal of Occupational Health Psychology, 7(3), 242-264.

Sverke, M., Hellgren, J., Näswall, K., Chirumbolo, A., De Witte, H., \& Goslinga, S. (2004). Job insecurity and union membership: European unions in the wake of flexible production. Brussels: P.I.E.Peter Lang.

Sverke, M., Hellgren, J., \& Öhrming, J. (1999). Organizational restructuring and health care work: A quasi-experimental study. In P. M. l. Blanc, M. C. W. Peeters, A. Buessing, \& W. B. Schaufeli (Eds.), Organizational psychology and health care: European contributions (pp. 15-32). Muenchen: Rainer Hampp Verlag.

Sverke, M., \& Sjöberg, A. (1994). Dual commitment to company and union in Sweden: An examination of predictors and taxonomy split methods. Economic and Industrial Democracy, 15(4), 531-564.

Tan, H., \& Tan, C. (2002). Temporary employees in Singapore: What drives them? The Journal of Psychology, 136(1), 83-102.

Thorsteinson, T. J. (2003). Job attitudes of part-time vs. full-time workers: A meta-analytic review. Journal of Occupational \& Organizational Psychology, 76(2), 151-177.

Wagena, E., \& Geurts, S. (2000). SWING Ontwikkleing en validering van de Survey Wek-thuis Interferentie Nijmegen [On development and validation of the Survey Work-Home Interference Nijmegen]. Gedrag \& Organisatie, 28(3), 138-158.

Ware, J. E. (1999). SF-36 Health Survey. In M. E. Maruish (Ed.), The use of psychological testing for treatment planning and outcomes assessment (2nd ed., pp. 1227-1246). Mahwah, NJ: Erlbaum Lawrence Associates. 
Warr, P. (1990). The measurement of well-being and other aspects of mental health. Journal of Occupational Psychology, 63(3), 193-210.

Warr, P., \& Jackson, P. (1985). Factors influencing the psychological impact of prolonged unemployment and re-employment. Psychological Medicine, 15(4), 795-807.

Warr, T. (1987). Work, unemployment, and mental health. Oxford: Claredon Press.

Wiens-Tuers, B. A., \& Hill, E. T. (2002). How did we get here from there? Movement into temporary employment. Journal of Economic Issues, 36(2), 303-311.

Vigneau, C., Ahlberg, K., Bercusson, B., \& Bruun, N. (1999). Fixed-term work in the EU. Stockholm: National Institute for Working Life.

Wikman, A. (2002). Temporära kontrakt och inlåsningseffekter [Temporary contracts and locked-in effects]. Arbetsliv i Omvandling, 2002:4.

Wikman, A., Andersson, A., \& Bastin, M. (1998). Nya relationer $i$ arbetslivet [New relations in working life]. Stockholm: National Institute for Working Life.

Virtanen, M. (2003). Temporary employment and health. Unpublished doctoral dissertation. Finnish Institute of Occupational Health, Helsinki.

Virtanen, M., Kivimäki, M., Joensuu, M., Virtanen, P., Elovainio, M., \& Vahtera, J. (2005). Temporary employment and health: A review International Journal of Epidemiology, 34(3), 610-622.

Virtanen, M., Kivimäki, M., Elovainio, M., Vahtera, J., Kokko, K., \& Pulkkinen, L. (2005). Mental health and hostility as predictors of temporary employment: Evidence from two prospective studies. Social Science \& Medicine, 61(10), 2084-2095.

Virtanen, M., Kivimäki, M., Ferrie, J. E., Elovainio, M., Honkonen, T., Pentti, J., et al. (2008). Temporary employment and antidepressant medication: A register linkage study. Journal of Psychiatric Research, 42(3), 221-229.

Virtanen, M., Kivimäki, M., Virtanen, P., Elovainio, M., \& Vahtera, J. (2003). Disparity in occupational training and career planning between contingent and permanent employees. European Journal of Work and Organizational Psychology, 12(1), 19-36.

Virtanen, P., Liukkonen, V., Vahtera, J., Kivimäki, M., \& Koskenvuo, M. (2003). Health inequalities in the workforce: The labour market core-periphery structure. International Journal of Epidemiology, 32(6), 1015-1021.

Virtanen, P., Vahtera, M., Kivimäki, J., Pentii, J. F., \& Ferrie, J. E. (2002). Employment security and health. Journal of Epidemiological Community Health, 56(8), 569-574.

Wooden, M. (2001). How temporary are Australia's casual jobs? Work, Employment \& Society, 15(4), 875-883. 